\title{
Siloxane adsorption on activated carbons: role of the surface chemistry on sorption properties in humid atmosphere and regenerability issues.
}

Vu Tung Lam Tran ${ }^{1}$, Patrick Gélin ${ }^{1 *}$, Corinne Ferronato ${ }^{1}$, Pascale Mascunan ${ }^{1}$, Vladislav Rac $^{2}$, Jean-Marc Chovelon ${ }^{1}$, Georgeta Postole ${ }^{1 *}$

${ }^{1}$ Univ Lyon, Université Claude Bernard Lyon 1, CNRS, IRCELYON, F-69626, Villeurbanne, France

${ }^{2}$ Faculty of Agriculture, Department of Chemistry, University of Belgrade, Nemanjina 6, 11080 Zemun, Serbia

Corresponding author: Tel: $+33(0) 472431148$

Fax: +33(0) 472445399

E-mail address: georgeta.postole@ircelyon.univ-lyon1.fr (G. Postole)

patrick.gelin@ircelyon.univ-lyonl.fr (P.Gélin)

\begin{abstract}
Commercial activated carbons (ACs) have been studied in dynamic adsorption of octamethylcyclotetrasiloxane (D4) in both dry and wet conditions. 1000 ppm (v/v) D4 with $\mathrm{N}_{2}$ as carrier gas and relative humidity $(\mathrm{RH})$ up to $70 \%$ were used. Samples were characterized by physicochemical techniques such as $\mathrm{N}_{2}$ and $\mathrm{H}_{2} \mathrm{O}$ adsorption/desorption at 196 and $20{ }^{\circ} \mathrm{C}$, respectively, XPS, Boehm titration, chemical and elemental analysis, thermogravimetric measurements. No correlation between adsorption capacity and textural properties in dry conditions could be established. In wet conditions, the presence of hydrophilic sites preferentially adsorbing $\mathrm{H}_{2} \mathrm{O}$ strongly decreases the ability of ACs to adsorb D4. The regenerability by thermal treatment after D4 adsorption in dry conditions was also addressed and followed by gas chromatography and in situ DRIFTS. The D4 polymerization into polysiloxanolate/PDMS was found to proceed on ACs containing alkali metals (K, Na) as revealed by the observed release of their decomposition products during the thermodesorption treatment. This property is detrimental to the regenerability of the AC by blockage of its porosity. The eventual formation of polysiloxanalolate type species during the adsorption could also be responsible for limiting the D4 uptake by partial blockage of the AC porosity.
\end{abstract}

Keywords: D4 adsorption, activated carbon, competitive adsorption with humidity, surface chemistry, biogas purification. 


\section{Introduction}

Volatile methyl siloxanes (VMS) appear to be one of the most important issues for the use of biogas as an alternative energy source [1]. The term siloxane refers to a class of silicones derivatives containing $\mathrm{Si}-\mathrm{O}$ bonding originating from many consumer products such as construction, medicine, cosmetics and personal care products [2]. The siloxanes in biogas can present cyclic or linear form, named $\mathrm{D}$ and $\mathrm{L}$ respectively, followed by a number corresponding to the number of silicon atoms present in the molecular structure [3,4]. The landfill gas exhibits high contents of trimethylsilanol (TMSOH) and octamethylcyclotetrasiloxane (D4) (58 and 17\% respectively) while D4 and decamethylcyclopentasiloxane (D5) are the main siloxane-type components (62 and 28\% respectively) of biogas produced in digester plants [5]. The siloxane concentration in biogas varies greatly and can go up to $140 \mathrm{mg} \mathrm{m}^{-3}$. This concentration is far beyond the limits required by the engine manufacturers $\left(5-28 \mathrm{mg} \mathrm{m}^{-3}\right.$ for internal combustion engines [6]).

The adsorption of siloxanes on activated carbon (AC) is the most widely used technique for removal of siloxanes from biogas. In standard conditions (room temperature, atmospheric pressure), ACs exhibit varying adsorption capacities depending on siloxane molecules: from 10 to $350 \mathrm{mg} \mathrm{L} 2 \mathrm{~g}_{\mathrm{AC}}{ }^{-1}$ [7,8], from 60 to $800 \mathrm{mg} \mathrm{D} 3 \mathrm{~g}_{\text {sorbent }}{ }^{-1}$ [9] and from 20 to $225 \mathrm{mg}$ D4 $\mathrm{g}_{\text {sorbent }}{ }^{-1}$ [10-12]. Textural properties are shown to influence the adsorption capacity. The D4 adsorption capacity was found to increase with the BET surface [10-13]. The external surface area (equal to the difference between BET surface area and micropore area) was proposed to be relevant for D4 adsorption in the study of Oshita et al. [12]. Yu et al. [11] when studying the adsorption of D4 on 11 kinds of commercial AC. The authors [19] found out that large micropores and narrow mesopores with diameter $\sim 1.7-3.0 \mathrm{~nm}$ are the most favorable for the D4 adsorption. Similar conclusion was drawn by Cabrera - Codony et al. [13] which found a relatively good correlation between the total micropore volume and the D4 adsorption capacity for a series of 12 kinds of commercial AC. It is worth mentioning that the commercial ACs studied presented mostly large micropores. Santos-Clotas et al. [14] support by their results that no direct relation can be established between the ultramicroporous volume and the adsorption capacity of investigated ACs. These findings are consistent with the fact that the diameter of siloxane molecules $(\sim 1 \mathrm{~nm}$ for $\mathrm{D} 4[11,12,15])$ is larger than narrow micropores preventing the adsorption on such sites.

Besides textural properties, the surface chemistry could be an important factor that influences the AC performance. The presence of heteroatoms $(\mathrm{O}, \mathrm{H}, \mathrm{N}, \mathrm{S} \ldots)$ bound to the edge of the 
graphene layers of the carbon material generates a variety of surface functional groups (FG) and the concentration of these groups depends on the thermal or chemical treatment used in the preparation procedure of ACs [16]. For example, Gong et al. [17] studied the D4 removal performance on an anthracite base AC pretreated with $\mathrm{NH}_{3}$ or $\mathrm{HCl}$ solution. The $\mathrm{NH}_{3}$ treatment increased the concentration of the basic groups, and this was shown to improve the D4 adsorption capacity. On the contrary, the $\mathrm{HCl}$ treatment introduced acid functional groups such as phenolic, lactonic and carboxylic groups, which show different behaviors in D4 adsorption. Carboxylic groups were claimed to have adverse effect on siloxane adsorption, while phenolic ones would improve siloxane adsorption. The role of the surface chemistry was also addressed in the study of Cabrera - Codony et al. [13]. No apparent relation was found between the D4 adsorption capacity and the O/C ratio measured by XPS and TPD, suggesting that the presence of oxygen containing FGs (i.e: carboxylic, lactone, anhydride, phenolic, carbonyl and ether groups) would be irrelevant to improving D4 adsorption. These contradictory results make it difficult to understand the interaction between siloxane and surface FGs.

Besides $\mathrm{CH}_{4}$ and $\mathrm{CO}_{2}$, the biogas contains $\mathrm{H}_{2} \mathrm{O}$ as the third main component (5 -10 vol.\%) [18]. At the outlet of the digester units the relative humidity (RH) of untreated or raw biogas often reaches $100 \%$ [19,20]. The water adsorption on carbonaceous materials has been extensively studied because of its importance in the moisture removal application [21]. It strongly relies on the FGs concentration and the porous structure. The presence of water vapor can hamper the VOC adsorption, depending on the hydrophobic/hydrophilic properties of the compounds as well as the relative humidity (RH) [22]. Ortega and Subrenat [8] studied the adsorption of L2 at room temperature on AC cloths and AC grains under dry and humid atmosphere with $\mathrm{RH}=70 \%$. No difference could be observed for AC cloth while the capacity loss was more perceptible for $\mathrm{AC}$ in grain (about $20 \mathrm{mg} \mathrm{g}^{-1}$ of difference). Although the authors attribute this difference to the more open micro porosity for $\mathrm{AC}$ in grain, no data concerning average pore size or surface chemistry were provided. Additional measurements for varying RH would be necessary to fully describe the effect of water vapor on L2 adsorption. Cabrera - Codony et al. [13] observed for the D4 adsorption on AC under dry and humid conditions (20 and $80 \% \mathrm{RH}$ ), that the adsorption capacity remains unchanged up to $20 \% \mathrm{RH}$ and decreases by $17 \%$ in the presence of $80 \% \mathrm{RH}$. This was attributed by the authors to the formation of hydrogen bonds between water molecules and the oxygen containing functional groups at $80 \% \mathrm{RH}$, which block the adsorption sites. However, this explanation is not fully convincing since the adsorption of water on functional groups can take place at $\mathrm{RH}$ 
below $40 \%$ [21], thus inducing capacity loss for AC at 20\%RH. In a more recent study [15], the authors found that the presence of water $(30 \% \mathrm{RH})$ increased the siloxane (D4, D5) uptake of phosphoric-activated carbons while small effect was found for steam-activated ones. A more deeply understanding of the water influence on siloxane adsorption would require measurements using a wider range of $\mathrm{RH}$ as well as the knowledge of the hydrophobic/hydrophilic character of the AC powder.

From an economical and environmental point of view, the ability of the adsorbent to be regenerated is another important issue. $\mathrm{AC}$ is generally used in non-regenerative adsorption technology and the exhausted adsorbent has to be replaced regularly. Consequently, the expenses for replacing sorbent bed are the predominant part of operating costs for biogas purification [23]. In the literature, various researches were conducted to assess the regenerability of the exhausted AC after siloxane adsorption [7,8,24]. Ortega and Subrenat [8] reported $25 \%$ loss of initial adsorption capacity after 3 cycles when studying the desorption of L2 from 2 kinds of AC by thermal treatment at $100{ }^{\circ} \mathrm{C}$ during $90 \mathrm{~min}$. A similar result was obtained by Gislon et al. [7] with 30\% loss of L2 adsorption capacity after heating exhausted AC from 80 to $160{ }^{\circ} \mathrm{C}$ for $4 \mathrm{~h}$. The complete desorption of L2 could only be achieved by maintaining the spent $\mathrm{AC}$ at $200{ }^{\circ} \mathrm{C}$ in adequate time. Giraudet et al. [24] studied the electrothermal regeneration at $145{ }^{\circ} \mathrm{C}$ of D4 - exhausted AC and found out that the process degraded significantly the adsorption capacity after 3 cycles of adsorption - desorption. The transformation of siloxane into non-volatile compounds (silica, polydimethylsiloxane) partly upon adsorption on AC is probably responsible for loss of adsorption capacity $[9,13]$. However, the parameters affecting the siloxane transformation were unexplored, making it difficult to design reusable ACs for siloxane removal.

In this paper, three commercial ACs used in air and gas treatment were chosen for the study of D4 adsorption. The AC powders were characterized by $\mathrm{N}_{2}\left(-196{ }^{\circ} \mathrm{C}\right)$ and $\mathrm{H}_{2} \mathrm{O}(20$ ${ }^{\circ} \mathrm{C}$ ) adsorption-desorption, chemical, proximate and elemental analysis, Boehm titration and XPS. Dynamic adsorption experiments using $1000 \mathrm{ppm}(\mathrm{v} / \mathrm{v}) \mathrm{D} 4 \mathrm{in} \mathrm{N}_{2}\left(12 \mathrm{~g} \mathrm{~m}^{-3}\right)$ were carried out. The influence of water vapor on D4 adsorption process was studied by varying RH (25, 40, 55 and 70\%). Thermodesorption experiments were also performed using Diffuse Reflectance Infrared Fourier Transform Spectroscopy (DRIFTS) and Gas Chromatography (GC) analysis to study the ability of the ACs to be regenerated. The relationship between the physicochemical properties of the ACs (textural characteristics, presence of acidbase/hydrophilic sites, surface impurities) and the adsorptive properties was discussed. 


\section{Experimental}

\subsection{Materials}

Octamethylcyclotetrasiloxane (D4) used as target siloxane for the adsorption experiments was obtained from Sigma Aldrich (Germany). D4 was selected for this work due to its high concentration in biogas as well as its impact on human health and environment.

Three kinds of activated carbon named EnvironCarb AP4-50, EnvironCarb STIX 4mm and EnvironCarb 207C 4x8, here denoted respectively as AP4, STIX and 207C, supplied by CHEMVIRON (Belgium) were tested. AP4 is produced by high temperature steam activation of coal and designed to adsorb a wide range of organic compounds. STIX is an impregnated extruded carbon which was contacted with an alkaline solution in order to develop the required characteristics for the removal of odorant organic compounds and acid gases such as $\mathrm{H}_{2} \mathrm{~S}, \mathrm{SO}_{2}, \mathrm{HCl}, \mathrm{CO}_{2}$, etc. $207 \mathrm{C}$ is a coconut based granular activated carbon for use in general air treatment applications. The ACs were ground and sieved to $40-75 \mu$ for physicochemical analysis and DRIFTS experiment. For the determination of the adsorption capacity using Gas Chromatography (GC), particles with sizes between 300 and $425 \mu$ were used.

\subsection{Physicochemical characterization}

The textural properties of the ACs were determined from $\mathrm{N}_{2}$ adsorption/desorption isotherms at $-196{ }^{\circ} \mathrm{C}$ using FLEX Micromeritics apparatus. Before the experiment, the AC samples were degassed at $150{ }^{\circ} \mathrm{C}$ under vacuum during $3 \mathrm{~h}$. Specific surface areas ( $\mathrm{S}_{\mathrm{BET}}$ ) were derived from the BET (Brunauer - Emmet - Teller) standard equation. The micropore surface areas $(\mathrm{S} \mu)$ and volumes $(\mathrm{V} \mu)$ were obtained via t-plots. Mesopore surface areas were calculated by subtracting the micropore areas from the total surface areas. The total pore volumes of the samples were obtained by converting the adsorption amount of liquid nitrogen into volume at relative pressure of 0.99 . The pore size distribution (PSD) in the micro-mesopore range was calculated using the 2D-NLDFT-HS model (heterogeneous surface of pores) [25]. The SAIEUS software available at www.NLDFT.com was used.

To further characterize textural and surface chemistry of the ACs surfaces, water vapor adsorption/desorption isotherms were measured using the same apparatus. About $200 \mathrm{mg}$ of AC previously outgassed at $150{ }^{\circ} \mathrm{C}$ during $3 \mathrm{~h}$ were used. For obtaining the isotherms, the samples were kept at constant temperature of $20{ }^{\circ} \mathrm{C}$ for relative humidity ranging from 0 to $96 \%$. 
Elemental analysis using Thermo Fisher Flash 2000 CHNS analyzer was carried out to assess the carbon, hydrogen, nitrogen and sulfur composition of the samples. The proximate analysis was carried out using a Pyris Diamond TG/DTA analyzer from PerkinElmer. The moisture content and the volatile content were determined as the weight loss at 110 and 900 ${ }^{\circ} \mathrm{C}$ respectively when heating about $5 \mathrm{mg} \mathrm{AC}$ in $\mathrm{N}_{2}$ flow $\left(40 \mathrm{ml} \mathrm{min}{ }^{-1}, 10{ }^{\circ} \mathrm{C} \mathrm{min}^{-1}\right)$. The ash content was determined as being the residual weigh after the pyrolysis of AC powder under air flow at $900{ }^{\circ} \mathrm{C}$. The carbon fixed content $\left(\mathrm{C}_{\text {fixed }}\right.$ in wt.\%) can be defined as: $\mathrm{C}_{\text {fixed }}=100-$ wt. $\%$ moisture - wt. $\%$ volatile - wt. $\%$ ash.

The metallic elements were estimated by Energy-dispersive X-ray (EDX) analysis using JEOL JSM 5800LV microscope. Because of their heterogeneous distribution on the AC surfaces, the average values were obtained taking into account the analyses of ten different areas. To confirm these values the chemical analysis was further performed. The experimental procedure used to analyze STIX residues after oxidation as well as the results obtained were reported elsewhere [26]. For 207C and AP4 powders, containing less inorganic impurities, only $\mathrm{K}$ and $\mathrm{Na}$ concentrations were determined by inductively coupled plasma-optical emission spectroscopy (ICP-OES, Activa instrument from Horiba Jobin Yvon). In order to dissolve them completely, the samples were treated with a mixture of $\mathrm{H}_{2} \mathrm{SO}_{4}+\mathrm{HNO}_{3}+\mathrm{HF}$ before dissolution in $\mathrm{HNO}_{3}$.

The surface chemistry of the ACs was investigated by X-Ray photoelectron spectroscopy (XPS) analysis and Boehm titration. XPS analysis was performed with a KRATOS Axis Ultra DLD using a monochromatized Mg Ka X-ray (1496.6 eV). The survey scan spectra were collected with an energy pass of $160 \mathrm{eV}$, whereas the high energy resolution spectra were performed with the pass energy of $20 \mathrm{eV}$.

Concentrations of acidic and basic groups of investigated carbons were determined according to Boehm methodology [27]. For titration of basic groups, $200 \mathrm{mg}$ of carbon sample was dispersed in $10 \mathrm{~mL}$ of $0.1 \mathrm{M} \mathrm{HCl}$ and stirred at $20{ }^{\circ} \mathrm{C}$ for $24 \mathrm{~h}$. The suspension was subsequently filtered and titrated conductometrically using $0.05 \mathrm{M} \mathrm{NaOH}$. Acidic groups were investigated in similar manner by mixing $500 \mathrm{mg}$ of carbon sample with $10 \mathrm{~mL}$ of 0.05 $\mathrm{M} \mathrm{NaOH}$ and using $0.05 \mathrm{M} \mathrm{HCl}$ for titration. A $0.05 \mathrm{M}$ solution of $\mathrm{Na}_{2} \mathrm{CO}_{3}$ was used as standard. For the determination of the point of zero charge $\left(\mathrm{pH}_{\mathrm{pzc}}\right)$, batch equilibrium method was used. $200 \mathrm{mg}$ of each activated carbon was stirred with $40 \mathrm{~mL}$ of $0.1 \mathrm{M} \mathrm{KNO}_{3}$ for $24 \mathrm{~h}$ at $20{ }^{\circ} \mathrm{C}$. Initial $\mathrm{pH}$ values were adjusted by adding the appropriate amounts of $\mathrm{KOH}$ or $\mathrm{HNO}_{3}$ solution $(0.1 \mathrm{M})$. Changes in solution $\mathrm{pH}$ as a result of the activated carbon addition were 
measured after liquid and solid phases separation. The point of zero charge was determined as the $\mathrm{pH}$ value at which a plateau is obtained on the graph $\mathrm{pH}_{\text {final }}=\mathrm{f}\left(\mathrm{pH}_{\text {initial }}\right)$.

\subsection{Breakthrough experiments of D4 adsorption}

Breakthrough experiments of siloxane adsorption were carried out by using the experimental set-up showed in Fig. 1. The gas containing D4 was obtained by continuous injection of liquid D4 $\left(1 \mu \mathrm{L} \mathrm{min}{ }^{-1}\right)$ into a nitrogen flow $\left(5 \mathrm{~L} \mathrm{~h}^{-1}\right)$. The D4 concentration $\left(12 \mathrm{~g} \mathrm{~m}^{-3}\right.$, equivalent to $1000 \mathrm{ppm}(\mathrm{v} / \mathrm{v})$ ) was much higher than in the biogas (up to $0.03 \mathrm{~g} \mathrm{~m}^{-3}$ for D4) for shortening the adsorption process. All the adsorption experiments were carried out at room temperature $\left(20 \pm 2{ }^{\circ} \mathrm{C}\right)$.

Samples (about $100 \mathrm{mg}$ of AC) were packed in a stainless steel tube (4.0 mm I.D x $47 \mathrm{~mm}$ long) sealed at both ends with quartz wool plugs. The bed height varied from 12 to $16 \mathrm{~mm}$ depending on the sample. Samples were pretreated before adsorption experiments at $150{ }^{\circ} \mathrm{C}$ for $2 \mathrm{~h}$ under a nitrogen flow $\left(5 \mathrm{~L} \mathrm{~h}^{-1}\right)$. The concentration of $\mathrm{D} 4$ in the outlet stream was monitored versus time using Perkin Elmer GC “Autosystem" equipped with a Flame Ionization Detector (FID).

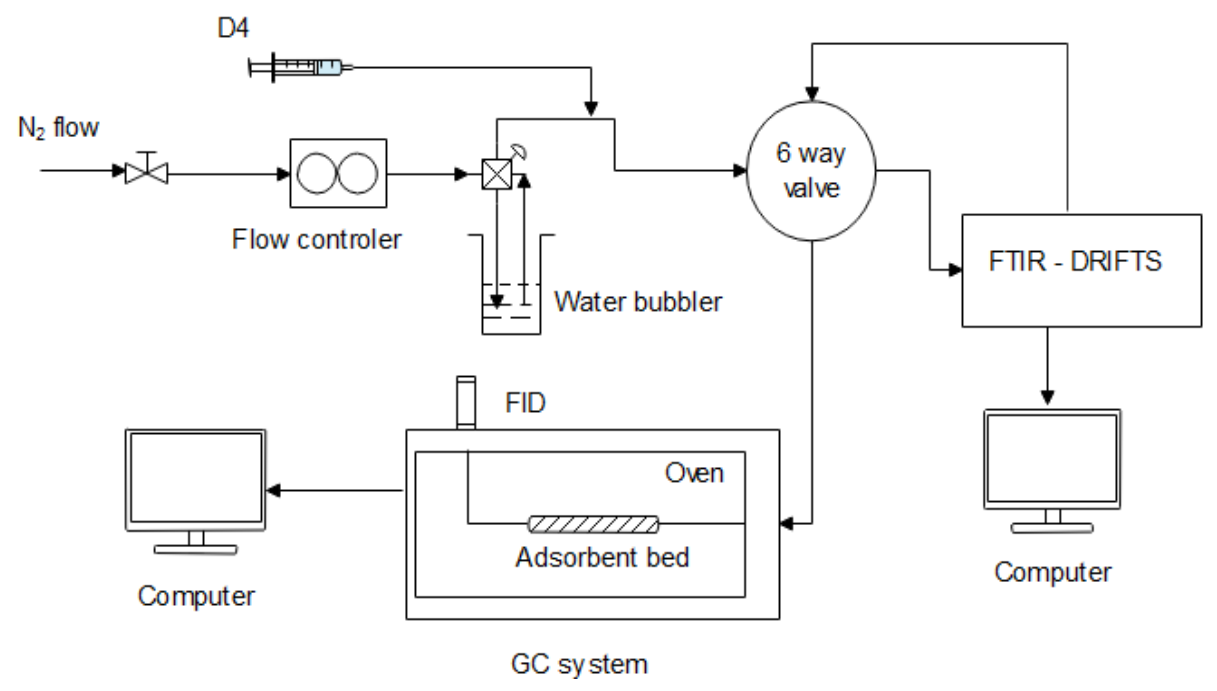

Fig. 1. Experimental set-up for the gas generation and adsorption/desorption experiments.

For adsorption experiments, breakthrough curves were plotted as the ratio of the outlet concentration to the inlet concentration $\left(\mathrm{C}(\mathrm{t}) / \mathrm{C}_{0}\right)$ versus time (in $\min$ ). The effective adsorption capacity (mg $D 4 \mathrm{~g}^{-1} A C$ ) was defined as the quantity of adsorbed D4 at saturation 
per gram of adsorbent. The adsorption capacity was therefore calculated by the following equation:

$$
\text { effective adsorption capacity }=\frac{Q}{m}\left(\int_{0}^{t_{s}} C_{\text {blank }}(t) d t-\int_{0}^{t_{s}} C(t) d t\right)
$$

where $Q$ was the inlet flow $\left(\mathrm{mL} \mathrm{min}^{-1}\right), m$ was the adsorbent mass, $\mathrm{C}_{\text {blank }}(\mathrm{t})$ and $\mathrm{C}(\mathrm{t})$ were the outlet D4 concentrations without (blank experiment) and with adsorbent at a given time, $t_{s}$ was the bed exhaustion time in the presence of adsorbent. Due to the negligible influence of dead volume and adsorption on walls on the signal response during the blank experiment, it could be assumed that:

$$
\int_{0}^{t_{s}} C_{\text {blank }}(t) d t=C_{o} \cdot t_{s}
$$

where $C_{0}$ was the inlet D4 concentration $(1000 \mathrm{ppm}(\mathrm{v} / \mathrm{v}))$.

The samples were then purged by $\mathrm{N}_{2}$ flow $\left(5 \mathrm{~L} \mathrm{~h}^{-1}\right)$ for $16 \mathrm{~h}$ at room temperature. Before and after the experiment, the column was disconnected from the line and weighed so that the adsorbed D4 quantity could be also measured. This was made possible due to the absence of D4 desorption at room temperature [9]. Experiments were repeated three times for each sample and standard deviation was calculated.

Afterwards, spent AC samples were thermodesorbed by heating up to $400{ }^{\circ} \mathrm{C}$ (heating rate of $5{ }^{\circ} \mathrm{C} \mathrm{min}^{-1}$ ) under $\mathrm{N}_{2}$ flow $\left(5 \mathrm{~L} \mathrm{~h}^{-1}\right)$. Three cycles of adsorption/thermodesorption were carried out and the adsorption capacity was measured after each adsorption step from breakthrough curves (GC measurements).

Adsorption experiments were also performed in the presence of water vapor. For this the D4 containing gas was bubbled through a saturator containing water and maintained at varying constant temperatures in order to obtain desired RHs. The amount of adsorbed D4 at equilibrium was measured by GC (breakthrough curve) while the total amount of adsorbed D4 and $\mathrm{H}_{2} \mathrm{O}$ was determined by weighing of the column containing the spent AC. In order to avoid the evaporation of adsorbed water and D4 during weighing the disconnected column was plugged at both ends by stainless steel caps. The mass of the adsorbed water was determined by subtracting the adsorbed D4 mass from the total mass gain. 


\subsection{In situ DRIFTS study of the D4 adsorption/thermodesorption on AC samples}

The sequence adsorption/thermodesorption of D4 on AC samples was also studied by in situ DRIFTS using a Thermo Nicolet Nexus 6700 FTIR spectrometer equipped with a high sensitivity MCT detector (Thermo-MCT, $750 \mathrm{~cm}^{-1}$ cutoff) cooled by liquid nitrogen to -196 ${ }^{\circ} \mathrm{C}$. Samples were introduced into a Spectra Tech double cup environmental chamber. All IR spectra were collected at a resolution of $4 \mathrm{~cm}^{-1}$ using 64 scans and a scanning velocity of $1.889 \mathrm{~cm} \mathrm{~s}^{-1}$. Experimental details for adsorption and thermodesorption experiments were previously reported [27]. Briefly, the samples were diluted with $\mathrm{KBr}$ powder. Mixtures of AC and $\mathrm{KBr}$ in mass ratios varying between 1:5 and 1:30 were studied and the most intense signals in the region of functional groups vibrations $\left(1400-800 \mathrm{~cm}^{-1}\right)$ were found for $\mathrm{AC}: \mathrm{KBr}$ dilution of 1:15. Before exposure to the D4 containing gas at room temperature, the samples were pretreated at $150{ }^{\circ} \mathrm{C}$ during $2 \mathrm{~h}$ under $\mathrm{N}_{2}$ atmosphere $\left(5 \mathrm{~L} \mathrm{~h}^{-1}\right)$. IR spectra were recorded each 5 min to monitor the spectral evolution during adsorption. Once the adsorption was complete (i.e. no more change of the IR spectrum), the D4 feed was stopped and the cell was purged overnight in $\mathrm{N}_{2}\left(5 \mathrm{~L} \mathrm{~h}^{-1}\right)$ at room temperature. For thermodesorption, the temperature was increased from 20 up to $400{ }^{\circ} \mathrm{C}$ by steps of $10{ }^{\circ} \mathrm{C}$ (linear rate of $5{ }^{\circ} \mathrm{C} \mathrm{min}{ }^{-1}$ for each step). The spectra were recorded each $10^{\circ} \mathrm{C}$ after temperature stabilization for $1 \mathrm{~min}$.

\section{Results and discussion}

\subsection{Physicochemical characterization of adsorbents}

\subsubsection{Chemical composition and surface chemistry}

\section{Chemical composition}

The chemical composition of the ACs was determined by combining the CHNS elemental analysis with temperature dependent weight loss measurements (proximate analysis), ICPOES chemical analysis and EDX results. The data obtained are summarized in Table 1 (elemental and proximate analysis results) and Table 2 (the ash contents determined by ICPOES and EDX). The proximate and elemental analyses of the carbon samples revealed that 207C presents the highest percentage of carbon element (89- 94 wt.\%) followed by AP4 (86 - 88 wt.\%) and STIX (62 - 65 wt.\%). The three powders present small amounts of other organic elements such as $\mathrm{H}, \mathrm{N}$ and $\mathrm{S}$ with the lowest content for 207C. Moisture has been determined as an important component of STIX (12.5 wt.\%) and 207C (4.2 wt.\%). 
Table 1. Proximate and elemental analysis of AC powders.

\begin{tabular}{|c|c|c|c|c|c|c|c|c|}
\hline \multirow[t]{2}{*}{ Sample } & \multicolumn{4}{|c|}{ Proximate analysis } & \multicolumn{4}{|c|}{ Elemental analysis } \\
\hline & $\begin{array}{l}\text { Moisture } \\
\text { (wt.\%) }\end{array}$ & $\begin{array}{l}\text { Volatiles } \\
\text { (wt.\%) }\end{array}$ & $\begin{array}{l}\mathrm{C}_{\text {fixed }} \\
\text { (wt.\%) }\end{array}$ & $\begin{array}{l}\text { Ash } \\
\text { (wt.\%) }\end{array}$ & $\begin{array}{l}\text { C } \\
\text { (wt.\%) }\end{array}$ & $\begin{array}{l}\mathrm{H} \\
\text { (wt.\%) }\end{array}$ & $\begin{array}{l}\mathrm{N} \\
\text { (wt.\%) }\end{array}$ & $\begin{array}{l}\text { S } \\
\text { (wt.\%) }\end{array}$ \\
\hline STIX & 12.5 & 10.5 & 62.1 & 14.9 & 64.9 & 1.85 & 0.25 & 0.12 \\
\hline AP4 & 1.3 & 0.8 & 88.3 & 9.6 & 85.7 & 0.43 & 0.22 & 0.58 \\
\hline $207 \mathrm{C}$ & 4.2 & 3.9 & 89.1 & 2.8 & 93.8 & 0.36 & 0.14 & 0.06 \\
\hline
\end{tabular}

The ash content, corresponding to metallic elements, is the highest for STIX (14.9 wt.\%) followed by AP4 (9.6 wt.\%). The metallic elements have been identified by EDX (Table 2) and chemical analysis for $\mathrm{K}$ and $\mathrm{Na}$. STIX contains $\mathrm{K}, \mathrm{Al}$ and $\mathrm{Si}$ as main impurities together with trace amounts of $\mathrm{Mg}, \mathrm{Na}, \mathrm{Fe}, \mathrm{Ca}$, and Ti. The AP4 sample showed the presence of metal impurities like $\mathrm{Si}, \mathrm{Al}, \mathrm{Ca}$ and minor amounts of $\mathrm{Ni}, \mathrm{Co}$ and $\mathrm{Mg}$. Interestingly low quantity of $\mathrm{K}$ was also detected as impurity in 207C sample. The total metallic content as derived from EDX is ca. 11, 3 and 1 wt.\% for STIX, AP4 and 207C, respectively. This result follows the same trend as the ash content determined by proximate analyses.

Table 2. Amount of metallic ingredients as determined by EDX and ICP-OES (wt.\%)

\begin{tabular}{llll}
\hline & STIX & AP4 & 207C \\
\hline $\mathrm{Na}$ & $0.13(0.13)^{*}$ & $0.07(0.15)^{*}$ & $-(0.05)^{*}$ \\
$\mathrm{Mg}$ & 0.05 & 0.07 & - \\
$\mathrm{Al}$ & 1.58 & 0.64 & - \\
$\mathrm{Si}$ & 1.81 & 1.44 & - \\
$\mathrm{P}$ & 0.05 & - & - \\
$\mathrm{K}$ & $6.61(4.57)^{*}$ & $0.02(0.03)^{*}$ & $1.29(0.79)^{*}$ \\
$\mathrm{Ca}$ & 0.52 & 0.67 & 0.03 \\
$\mathrm{Fe}$ & 0.32 & 0.51 & - \\
$\mathrm{Ti}$ & 0.07 & - & - \\
Total & 11.14 & 3.42 & 1.32 \\
\hline *The values in the brackets were obtained by ICP-OES
\end{tabular}

\section{Boehm titration}


Table 3 presents the quantities of basic/acidic groups per gram AC determined by the Boehm titration [27]. The three AC powders show a predominant basic character, given the greater content of basic sites as compared to acidic sites. The total amount of basic sites increases in the order: 207C < AP4 < STIX. These results are also reflected in the obtained values of the point of zero charge $(\mathrm{pH}$ value at which a solid submerged in an electrolyte exhibits zero net electrical charge on the surface). Attempts for determining the nature of oxygen-bearing surface groups were not fruitful due to their low amount. The basic character of ACs is generally considered as being due to delocalized $\pi$ electrons on condensed aromatic sheets [28]. This could be also correlated with the presence of inorganic impurities with basic character (Table 2).

Table 3. The amount of acid/basic sites and the values of $\mathrm{pH}_{\mathrm{pzc}}$ of $\mathrm{AC}$ powders

\begin{tabular}{cccc}
\hline Sample & Total basic $\left(\mathrm{mmol} \mathrm{g}^{-1}\right)$ & Total acidic $\left(\mathrm{mmol} \mathrm{g}^{-1}\right)$ & $\mathrm{pH}_{\mathrm{pzc}}$ \\
\hline STIX & 1.84 & $<0.1$ & 9.8 \\
AP4 & 1.13 & 0.12 & 9.3 \\
207C & 0.65 & $<0.1$ & 8.3 \\
\hline
\end{tabular}

\section{XPS analysis}

XPS analysis was further carried out to get insight into the chemical environment of the ACs surfaces. Surface composition data obtained from the quantitative analysis of the XPS peaks show that carbon contents in the bulk (as determined by proximate or elemental analyses, Table 1) are lower than that found on the surface for STIX and AP4 with 94.6 and 90.5 wt.\% $\mathrm{C}$, respectively. It is likely the ashes are mainly located in the bulk of these materials with only small amounts present on their external surface. For 207C, the carbon weight content decreases on the surface ( $85.1 \mathrm{wt} . \% \mathrm{C}$ ) when compared with that determined in the bulk. This can be explained by the presence of ashes content mainly on the surface of the AC together with a higher amount of oxygen (11 wt.\%) than determined for AP4 and STIX with 6.2 and 5.4 wt. $\%$ O, respectively.

The presence of oxygen on all AC surfaces can be related with various oxygenated functional groups. Their nature was further analyzed by the decomposition of $\mathrm{C} 1 \mathrm{~s}$ core energy level spectra. 
Typical high-resolution XPS spectra of the $\mathrm{C}$ 1s region are shown in Fig. 2. They are very similar for all ACs (Fig. 2A) and show an asymmetric tailing towards higher binding energies as result of the presence of oxygen functional groups. Indeed, C 1s spectra could be fitted by four main components (Fig. 2B) with different binding energy values corresponding to the $\mathrm{C}=\mathrm{C} \mathrm{sp}{ }^{2}$ hybridized bonds of graphitic carbon $(284.6 \mathrm{eV}), \mathrm{C}-\mathrm{O}$ in phenol, alcohol, ether groups or C-N groups $(285.4-285.7 \mathrm{eV}), \mathrm{C}=\mathrm{O}(286.9-287.3 \mathrm{eV})$ and $\mathrm{COOH}(289.7-290.4$ eV) $[29,30]$. The peak corresponding to the graphitic carbon shows the greatest intensity and the decomposition yielded similar results for all ACs with 55 to 57 at.\% of the area under the curve corresponding to graphitic carbon, whereas the carbon was as high as 89.5-95.9 at.\% on the surface. Surface oxygen content ranged from 8.7 at.\% for $207 \mathrm{C}$ to 4.8 at.\% for AP4 and 4.1 at.\% for STIX and the intensity of the different functional groups is quite low for unambiguous quantification. For STIX and 207C, the presence of K $2 \mathrm{p}$ is also evidenced (a doublet with binding energies between $291-298 \mathrm{eV}$ ) in agreement with EDX and chemical analysis observations.

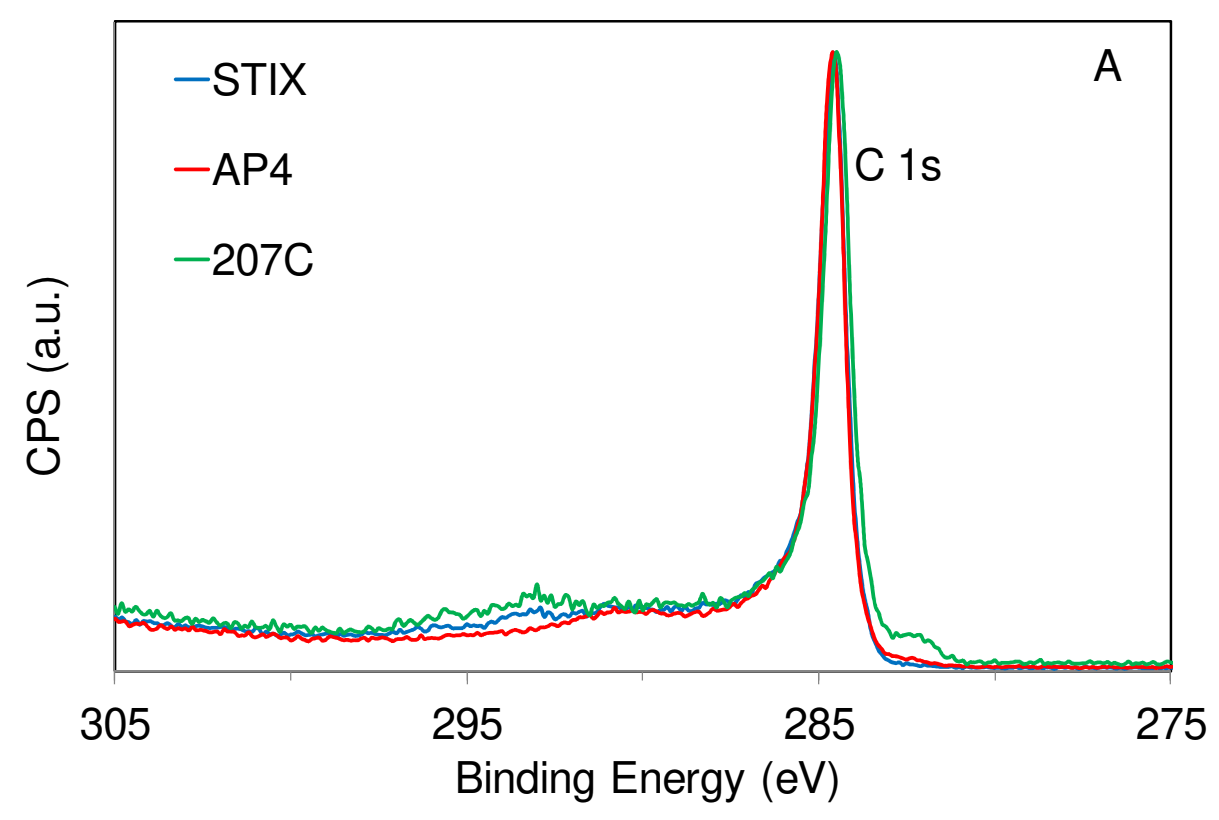




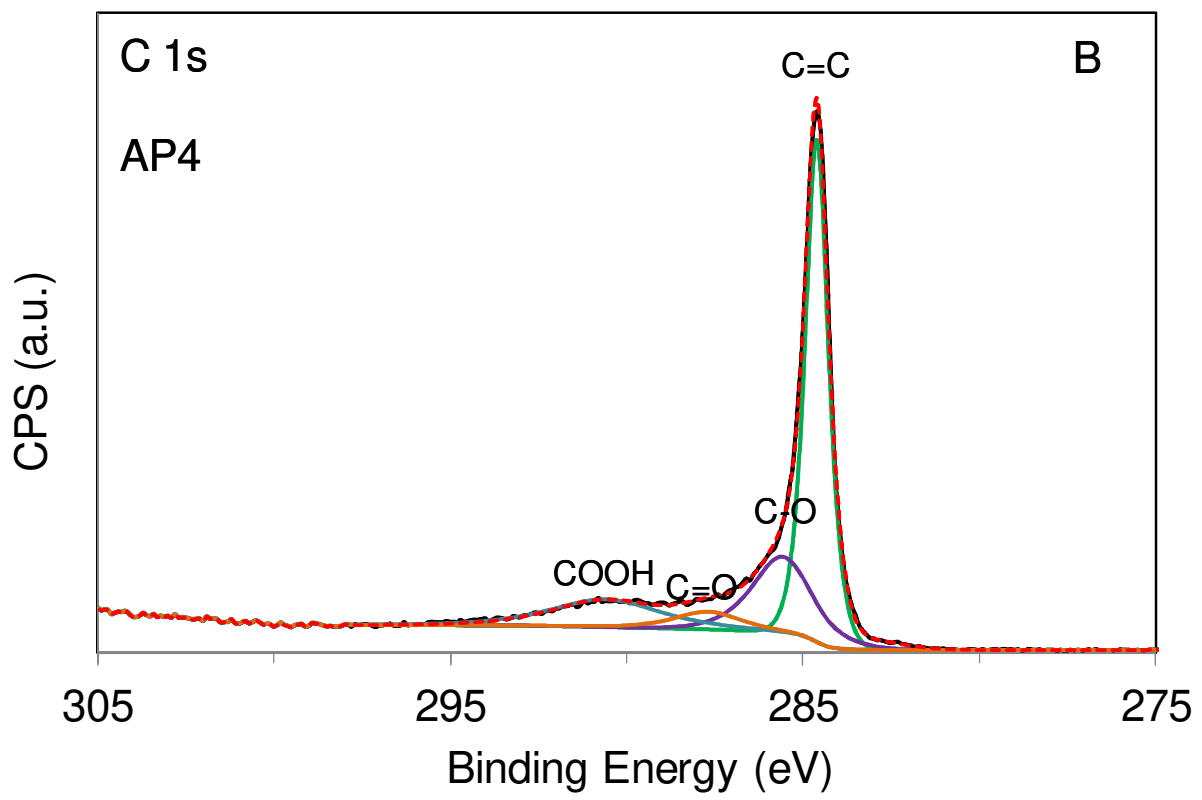

Fig. 2. A) Comparison of XPS spectra of C 1s of activated carbons; B) Decomposition of C 1s core energy level spectra of AP4.

3.1.2 Combining $\mathrm{N}_{2}$ and $\mathrm{H}_{2} \mathrm{O}$ adsorption for surface chemistry and pore structure characterization

$\mathrm{N}_{2}$ adsorption/desorption at $-196{ }^{\circ} \mathrm{C}$ was used to obtain pore volume, pore size and surface area information on $\mathrm{AC}$ samples while water adsorption/desorption isotherms at $20{ }^{\circ} \mathrm{C}$ were measured to evaluate the influence of surface chemistry $[31,32]$.

Textural characteristics of STIX, AP4 and 207C activated carbons are reported in Table 4. The related $\mathrm{N}_{2}$ adsorption/desorption isotherms are shown in Fig. 3. For all powders, the isotherm exhibits a steep rise for low $\mathrm{P} / \mathrm{P}_{0}$ followed by a slow and continuous increase of the amount of $\mathrm{N}_{2}$ adsorbed up to a relative pressure of 1 . The curve shape and the absence of a hysteresis loop account for type I isotherms according to IUPAC classification, which corresponds to a predominant microporous structure [33]. From Table 4, the three ACs samples present high percentages (between 70 and 84\%) of micropore surface area with respect to total BET surface areas ranging from 760 to $1200 \mathrm{~m}^{2} \mathrm{~g}^{-1}$. The total- and micro- pore volumes decrease in the following order 207C > AP4 > STIX.

The D4 diameter and the pore size distribution (PSD) of the activated carbons may be considered as important parameters of AC adsorption capacities. Indeed, D4 cannot enter pores whose size would be less than its size, and the adsorption potential is too weak when the 
pore size is much larger than the D4 diameter. The PSDs (Fig. 3) show that all three ACs present narrow micropores with diameter lower than $1 \mathrm{~nm}$. Such pores are likely not accessible to D4 having a kinetic diameter equal to $1 \mathrm{~nm}$ [11-13]. Pores in the range 1-3 nm are also observed indicating the presence of large micropores and narrow mesopores expected to be relevant for D4 adsorption.

Table 4. Textural properties: BET surface area $\left(\mathrm{S}_{\mathrm{BET}}\right)$, micropore $\left(\mathrm{S}_{\mu}\right)$ and mesopore $\left(\mathrm{S}_{\mathrm{m}}\right)$ surfaces, percentage of micropore surface area on total BET surface, total- and micro- pore volume $\left(\mathrm{V}_{\mathrm{T}}, \mathrm{V} \mu\right)$, percentage of micropore volume.

\begin{tabular}{llllllll}
\hline ACs & $\begin{array}{l}\mathrm{S}_{\mathrm{BET}} \\
\left(\mathrm{m}^{2} \mathrm{~g}^{-1}\right)\end{array}$ & $\begin{array}{l}\mathrm{S}_{\mu} \\
\left(\mathrm{m}^{2} \mathrm{~g}^{-1}\right)\end{array}$ & $\begin{array}{l}\mathrm{S}_{\mathrm{m}}{ }^{*} \\
\left(\mathrm{~m}^{2} \mathrm{~g}^{-1}\right)\end{array}$ & $\begin{array}{l}\mathrm{S}_{\mu} / \mathrm{S}_{\mathrm{BET}} \\
(\%)\end{array}$ & $\begin{array}{l}\mathrm{V}_{\mathrm{T}} \\
\left(\mathrm{cm}^{3} \mathrm{~g}^{-1}\right)\end{array}$ & $\begin{array}{l}\mathrm{V} \mu \\
\left(\mathrm{cm}^{3} \mathrm{~g}^{-1}\right)\end{array}$ & $\begin{array}{l}\mathrm{V} \mu / \mathrm{V}_{\mathrm{T}} \\
(\%)\end{array}$ \\
\hline STIX & 766 & 536 & 230 & 70 & 0.55 & 0.28 & 51 \\
AP4 & 991 & 793 & 198 & 80 & 0.62 & 0.38 & 61 \\
$207 C$ & 1207 & 1019 & 188 & 84 & 0.66 & 0.44 & 67 \\
\hline
\end{tabular}

${ }^{*} \mathrm{~S}_{\mathrm{m}}=\mathrm{S}_{\mathrm{BET}}-\mathrm{S}_{\mu}$.

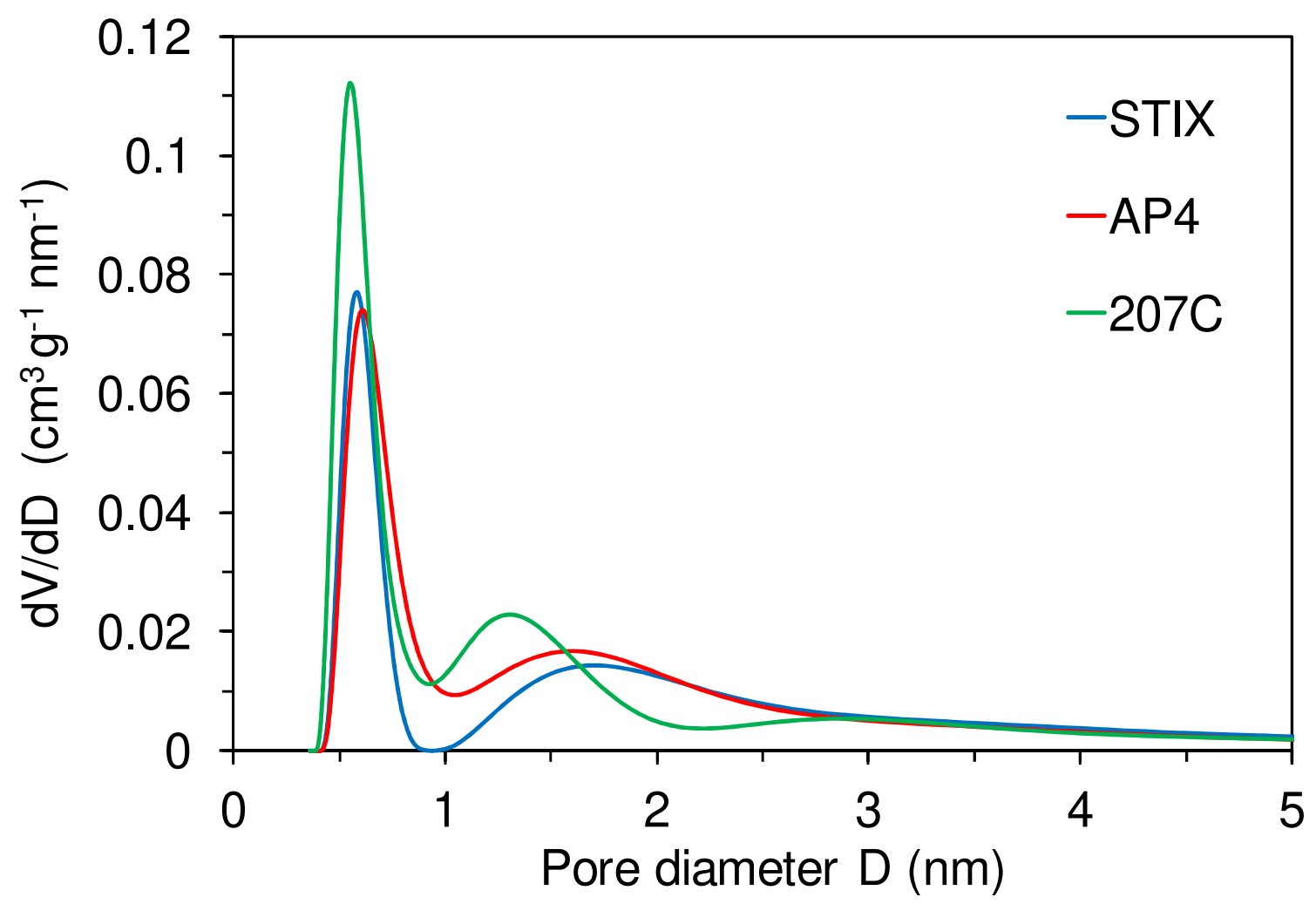

Fig. 3. Pore size distribution of STIX, AP4 and 207C as calculated by using the 2D-NLDFTHS model assuming the surface heterogeneity of pores. 
Fig. 4 also shows the water vapor adsorption $\left(20^{\circ} \mathrm{C}\right)$ isotherms for various samples. Different curve shapes were obtained in comparison with the isotherms derived from nitrogen adsorption. STIX shows a type IV isotherm [34] with a quick rise of water uptake at very low relative pressure $\left(\mathrm{P} / \mathrm{P}_{0}<0.02\right)$ which increases progressively up to $390 \mathrm{~cm}^{3} \mathrm{~g}^{-1}$ at $\mathrm{P} / \mathrm{P}_{0}=0.94$. Such behavior results from the contribution of two types of adsorption: type I, taking place at low relative pressures, associated to the water adsorption on hydrophilic sites (functional groups [35], inorganic impurities) and type $\mathrm{V}$ associated to the pores filling. Filling of both micro- and mesopores proceeds, as revealed by hysteresis curves. Contrary to STIX, very little water vapor adsorption could be observed for AP4 at low relative pressure $\left(\mathrm{P} / \mathrm{P}_{0}<0.2\right)$. At higher relative pressure, the water uptake rises continuously with a slope change at $\mathrm{P} / \mathrm{P}_{0}$ of 0.55 before to attain the maximum value of $455 \mathrm{~cm}^{3} \mathrm{~g}^{-1}$ at $\mathrm{P} / \mathrm{P}_{0}=0.96$. This behavior is characteristic of multimodal type pore size distribution. Based on the studies of Thommes et al. [31], the water adsorption in micropores with size mainly ranging in the interval 1-2 nm occurs exclusively at relative pressures between 0.4 and 0.7. Accordingly, the water adsorption occurring below $\mathrm{P} / \mathrm{P}_{0}=0.55$ on $\mathrm{AP} 4$ could be attributed to the filling of ultramicropores $(<1 \mathrm{~nm})$. The region of $\mathrm{P} / \mathrm{P}_{0}$ ranging from 0.55 to 0.7 would be associated to the filling of larger micropores and the region of $\mathrm{P} / \mathrm{P}_{0}$ above 0.7 to the filling of narrow mesopores. Similar multimodal type isotherm of water adsorption is observed for 207C, in correlation with PSD involving ultramicropores, larger micropores and mesopores. Interestingly the water uptake for $\mathrm{P} / \mathrm{P}_{0}$ ranging from 0.2 to 0.55 is higher than for $\mathrm{AP} 4$, which correlates with a higher volume of ultramicropores as determined from $\mathrm{N}_{2}$ adsorption isotherm. Water adsorption occurring below $\mathrm{P} / \mathrm{P}_{0}<0.2$ can be attributed to the presence of hydrophilic sites, as for STIX but in lower amounts. 207C presents the highest value of water uptake at $\mathrm{P} / \mathrm{P}_{0}=0.95\left(469 \mathrm{~cm}^{3} \mathrm{~g}^{-1}\right)$.

The results obtained confirm that the use of water as a probe for surface chemistry and pore structure characterization of ACs is valuable [21,31,34,35]. It turns out that the shape of the isotherms of water adsorption at $\mathrm{P} / \mathrm{P}_{0} \leq 0.2$ can be primarily used to indicate the presence or not of surface sites specifically interacting with $\mathrm{H}_{2} \mathrm{O}$ (hydrophilic sites). These sites can be surface oxygen containing FGs and/or impurities. Based on XPS data, surface oxygenated species are similar in type and number irrespective of the AC sample, thus excluding these species as being hydrophilic sites responsible for the differences observed in between ACs in the range of low relative pressures. It is suggested that some impurities present at the AC surface could exhibit hydrophilic properties. Among inorganic impurities, K was detected as a surface impurity by XPS in STIX and 207C. ICP-OES and EDX analyses confirmed the 
presence of $\mathrm{K}$ in STIX and 207C and the concentration varies with the same trend as that revealed by water isotherm at $\mathrm{P} / \mathrm{P}_{0}<0.2$ : more hydrophilic sites (more $\mathrm{K}$ ) on STIX than on 207C. K was not detected in AP4. This sample weakly adsorbs $\mathrm{H}_{2} \mathrm{O}$ at low relative pressures. This strongly suggests surface K containing species as being surface hydrophilic sites.

The so called hydrophilicity index (HI) was proposed by Thommes et al. [31,32] to characterize the surface chemistry of AC samples. Briefly the hydrophilicity index involves the comparison of the adsorption uptakes of water, which is sensitive to surface chemistry and does not completely wet the surface with the uptake of a gas $\left(\mathrm{N}_{2}\right.$ or Ar) which completely wets the surface at the boiling temperature. Measures are made at $\mathrm{P} / \mathrm{P}_{0}=0.92(\mathrm{Ar})-0.95$ $\left(\mathrm{N}_{2}\right)$. The greater the deviation to 1 (1 indicating the complete pore filling with water), the greater the hydrophobicity of the surface. All AC samples of the present study give HI values equal to $0.59 \pm 0.01\left(\mathrm{P} / \mathrm{P}_{0}=0.94\right)$, which indicates that the surface chemistry of these samples is only weakly hydrophilic, as already found for ordered mesoporous carbon samples $(\mathrm{HI} \approx$ $0.6)[31]$.

It may be inferred that this property could be governed by oxygen containing FGs which are similar in type and in number on various samples, in agreement with XPS data.

It may be anticipated that co-adsorption of D4 and water vapor would then lead to some competition which will be similar for all samples at RH close to $100 \%$. On the contrary, varying behaviors could possibly be detected among samples when decreasing RH, due to the predominant influence of hydrophilic sites whenever present.

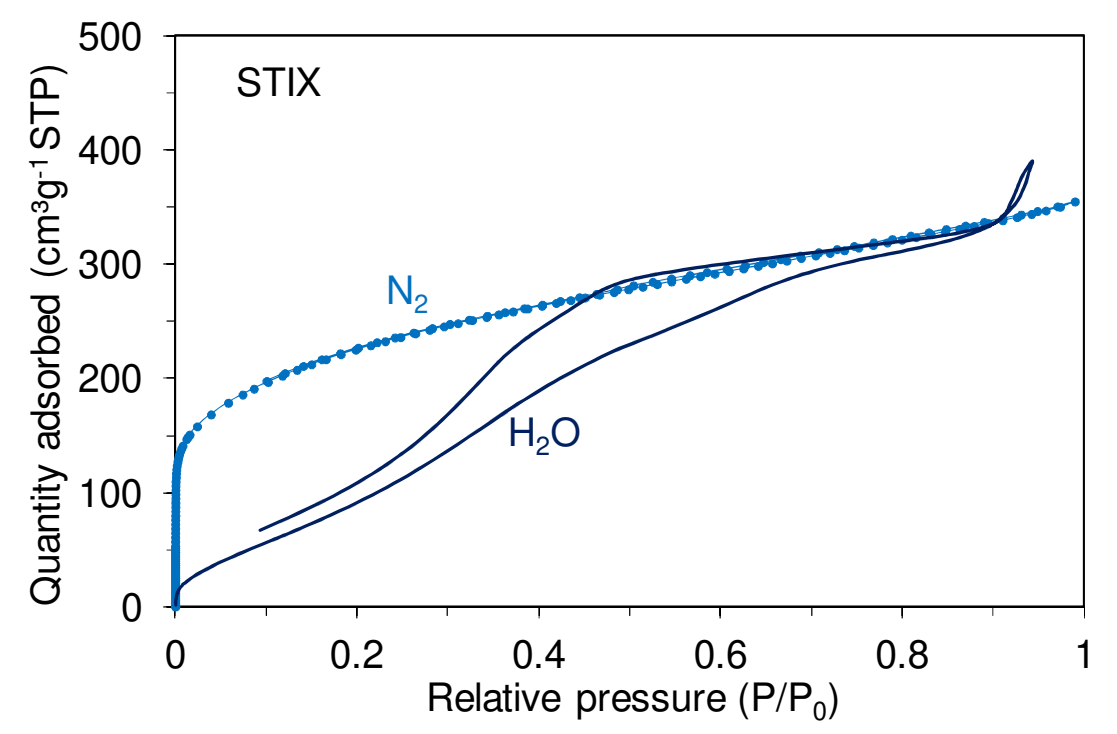



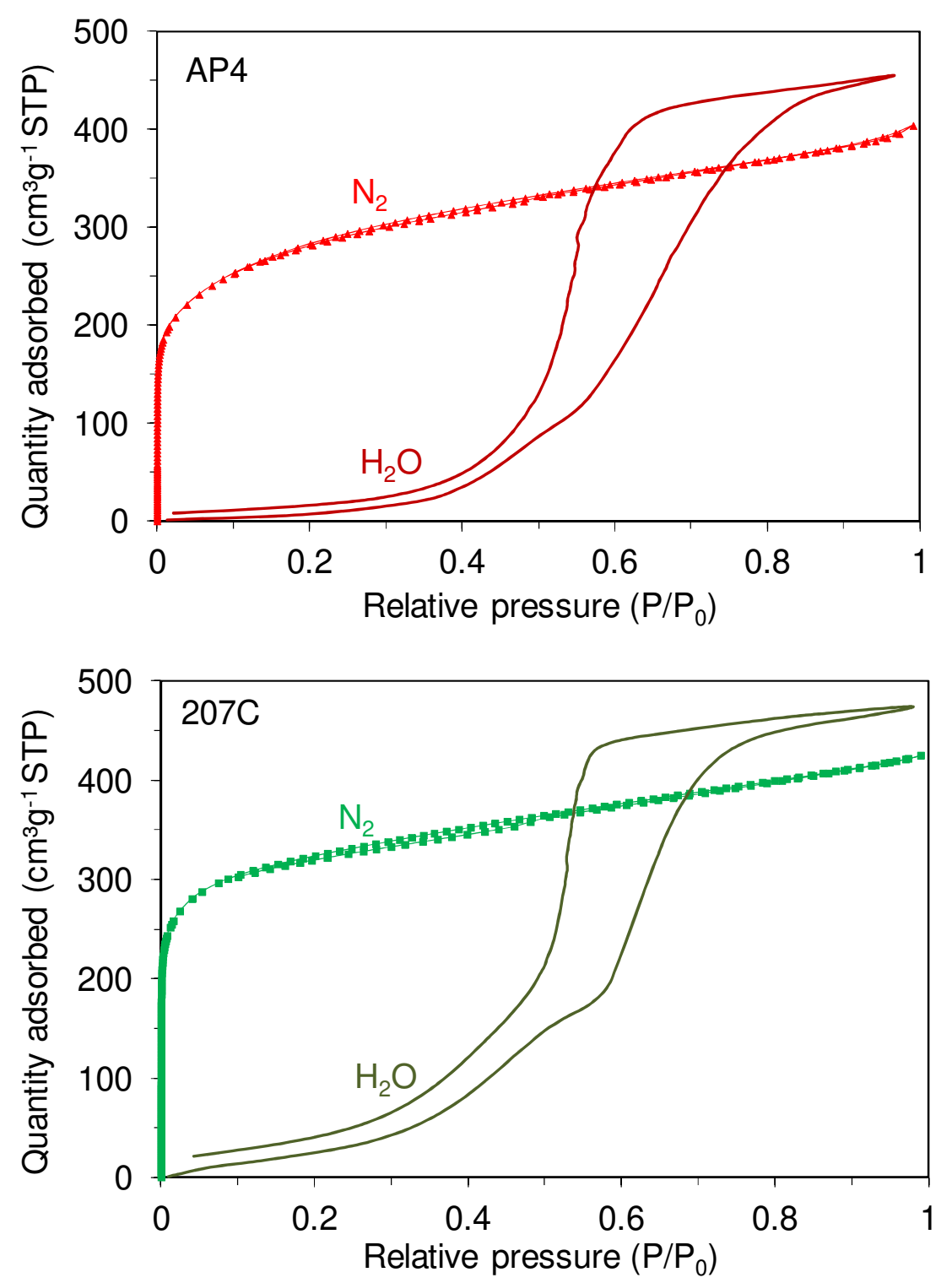

Fig. 4. $\mathrm{N}_{2}\left(-196{ }^{\circ} \mathrm{C}\right)$ and $\mathrm{H}_{2} \mathrm{O}\left(20^{\circ} \mathrm{C}\right)$ adsorption/desorption isotherms for STIX, AP4 and $207 \mathrm{C}$ pretreated under vacuum at $150{ }^{\circ} \mathrm{C}$.

\subsection{Influence of relative humidity on $\mathrm{D4}$ adsorption at room temperature}

3.2.1. Determination of D4 adsorption capacity at room temperature in dry conditions.

The D4 adsorption capacity of various AC samples was calculated from breakthrough curves of D4 dynamic adsorption at room temperature $\left(20 \pm 2{ }^{\circ} \mathrm{C}\right)$ (Fig. 5) and reported in Table 5. It is observed that the time needed to saturate the ACs with D4 is 40 min for STIX and 207C and 60 min for AP4, which indicates a higher adsorptive capacity of AP4 than STIX and 207C. 
Table 5 shows the adsorption capacity derived from breakthrough curves together with those obtained by sample weighing at saturation (see experimental section). For each sample, both methods lead to the same value of adsorption capacity within the error margin. Among studied samples, AP4 is a much better D4 adsorbent (adsorption capacity of $269 \pm 5 \mathrm{mg} \mathrm{g}^{-1}$ ) than STIX and 207C, which exhibit similar performances $\left(161 \pm 6\right.$ and $155 \pm 5 \mathrm{mg} \mathrm{g}^{-1}$ respectively). These values fall in the range reported by other research groups (50 to $300 \mathrm{mg}$ $\mathrm{g}^{-1}$ ) [9-12]. Higher adsorption capacities (up to $1700 \mathrm{mg} \mathrm{g}^{-1}$ ) were also reported [13]. The adsorption capacity is generally associated with the specific surface area of ACs and their porous structure [11-13].

Fig. 6 reports the cumulative surface area of studied samples vs pore diameter D in the domain of micropores and narrow mesopores $(0<\mathrm{D}<4 \mathrm{~nm})$. Based on literature [11,13,14] only large micropores and narrow mesopores would mostly be responsible for D4 adsorption in agreement with the D4 critical diameter of $1.08 \mathrm{~nm}$ [15] In this domain, it can be observed that STIX and AP4, which present respectively the lowest and highest D4 adsorption capacity, show similar variation of cumulative surface area. Other parameters than only textural properties are likely to affect the adsorption of D4 on AC.

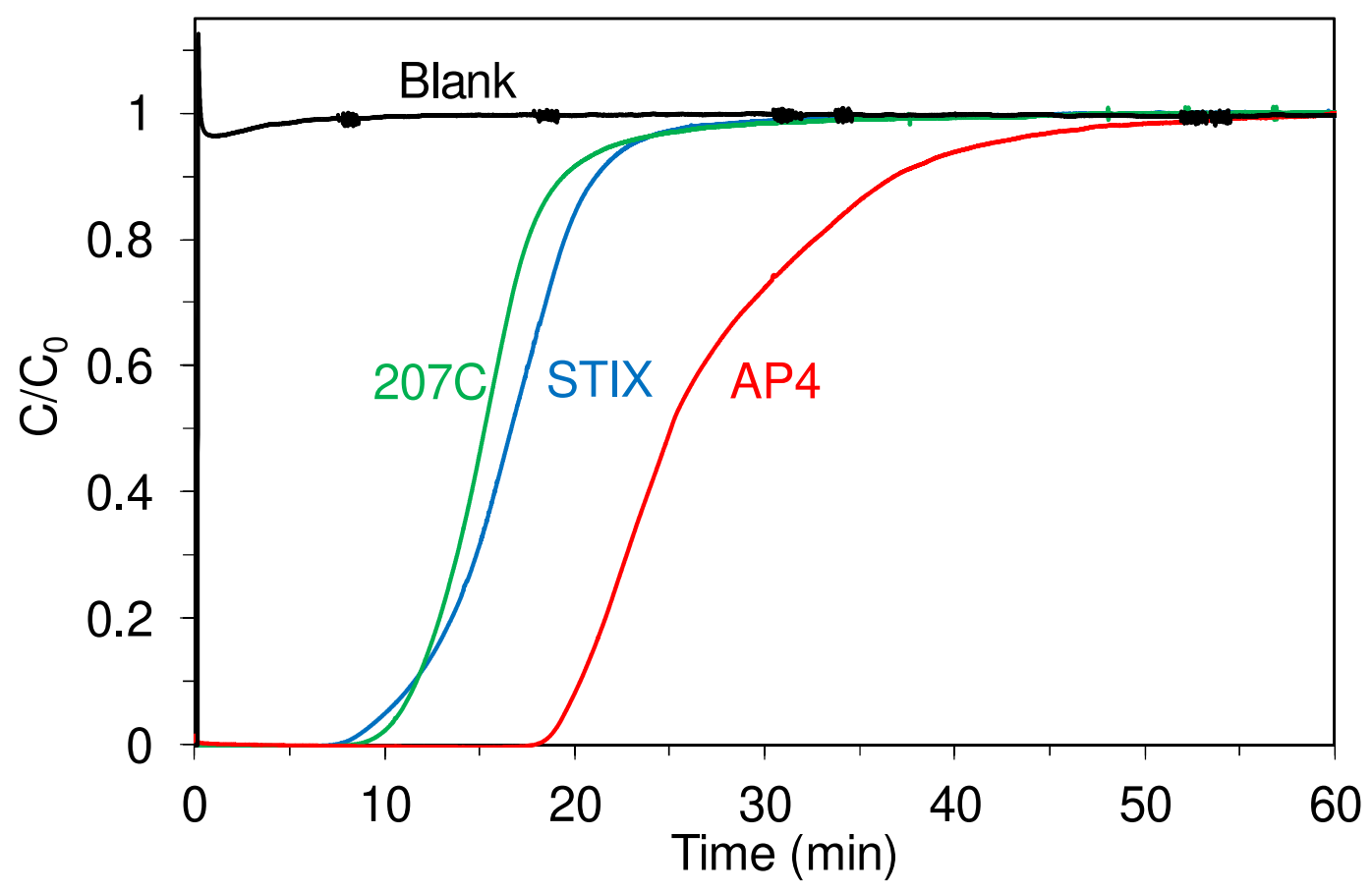

Fig. 5. Breakthrough curves of dynamic D4 adsorption experiments on STIX, AP4 and 207C. The blank experiment is also reported (black line). Experimental conditions: adsorption temperature $=20 \pm 2{ }^{\circ} \mathrm{C} ; \mathrm{C}_{0}=1000 \mathrm{ppm}(\mathrm{v} / \mathrm{v}) \mathrm{D} 4$ in $\mathrm{N}_{2}$; flow rate $=5 \mathrm{~L} \mathrm{~h}^{-1}$; sample weight $=$ $100 \mathrm{mg}$. All AC samples were pretreated under $\mathrm{N}_{2}$ flow at $150{ }^{\circ} \mathrm{C}$ for $2 \mathrm{~h}$. 
Table 5. D4 adsorption capacity of 207C, STIX and AP4 at room temperature.

\begin{tabular}{ccc}
\hline \multirow{2}{*}{ Sample } & \multicolumn{2}{c}{ Adsorption capacity $\left(\mathrm{mg} \mathrm{g}^{-1}\right)$} \\
\cline { 2 - 3 } & Breakthrough curve & $\begin{array}{c}\text { Sample weighing after } \\
\text { experiment }\end{array}$ \\
\hline STIX & $161 \pm 6$ & $153 \pm 3$ \\
AP4 & $269 \pm 5$ & $260 \pm 7$ \\
207C & $155 \pm 6$ & $149 \pm 4$ \\
\hline
\end{tabular}

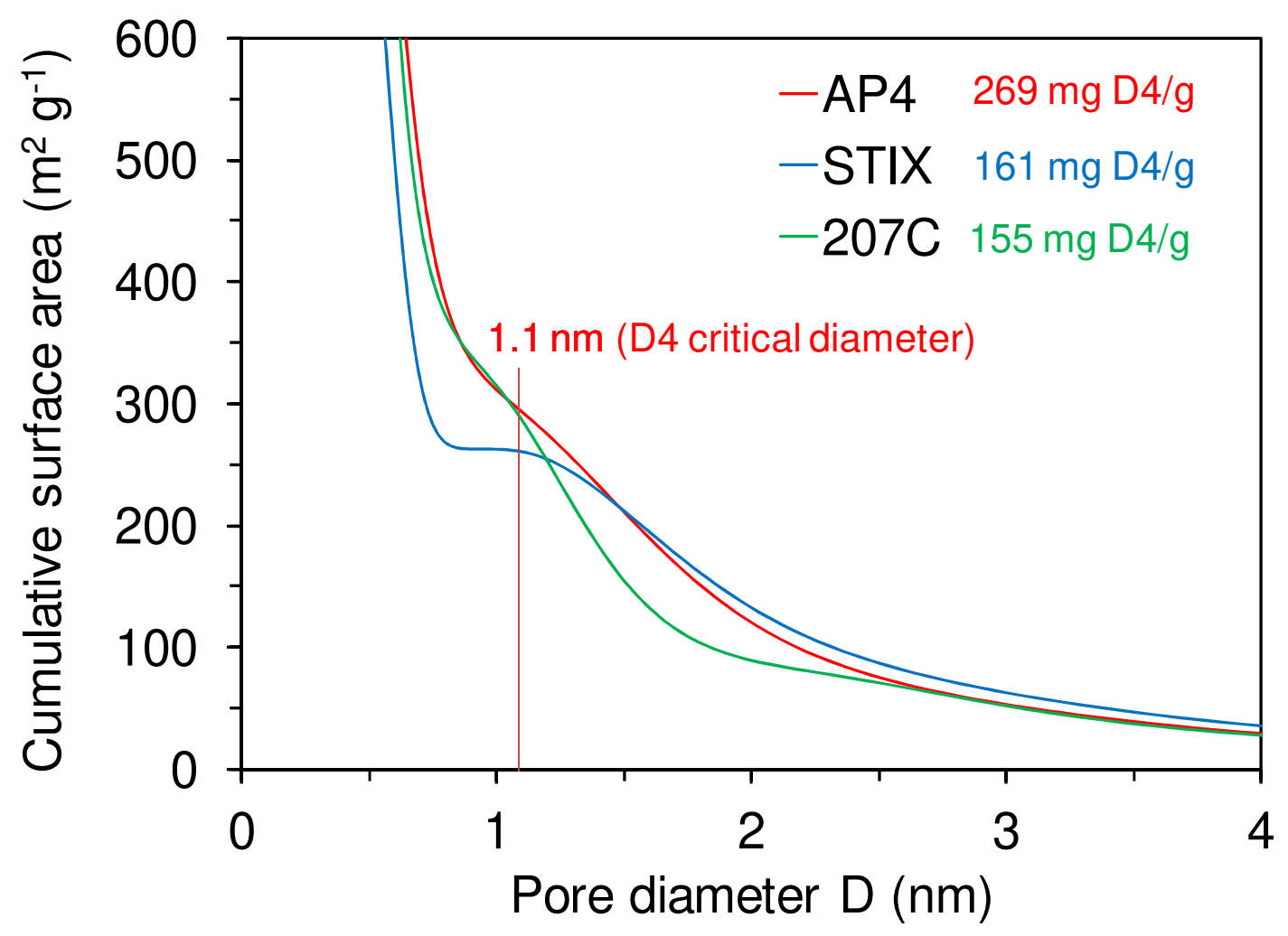

Fig. 6. Cumulative surface area vs pore diameter $D$ in the domain of micropores and narrow mesopores $(0<\mathrm{D}<4 \mathrm{~nm})$ calculated using the 2D-NLDFT-HS model. The critical diameter of D4 was determined in [15].

\subsubsection{Study of D4 adsorption on ACs at room temperature in wet conditions}

Fig. 7A and B shows the D4 adsorption capacities as well as water uptakes obtained in D4/ $\mathrm{H}_{2} \mathrm{O}$ mixtures with varying $\mathrm{RH}(25,40,55,70 \%)$. Water uptakes obtained in the presence of D4 are compared to the isotherm of water adsorption (Fig. 7B). $\mathrm{RH}$ and relative water pressure $\left(\mathrm{P} / \mathrm{P}_{0}\right)$ are related by: $\mathrm{RH}(\%)=100 * \mathrm{P} / \mathrm{P}_{0}$. 
The D4 adsorption capacity at $20{ }^{\circ} \mathrm{C}$ is strongly dependent on the sample and the RH (Fig. 7A). For AP4, the D4 adsorption capacity decreases by 14 and $21 \%$ at RH $=55$ and $70 \%$ respectively while at $\mathrm{RH}<55 \%$ almost no variation is observed. STIX shows a significant decrease of D4 adsorption capacity (57\%), which starts at $\mathrm{RH}=40 \%$ and weakly varies at higher RH values (63\% decrease of D4 adsorption capacity at 70\% RH). 207C presents a linear loss of adsorption capacity with increasing $\mathrm{RH}$, leading to an intermediate trend between AP4 and STIX (33\% decrease of D4 adsorption capacity at 70\% RH).

Regarding $\mathrm{H}_{2} \mathrm{O}$ adsorption (Fig. 7B), an increase of the water uptake is observed in the presence of $\mathrm{D} 4$ for $\mathrm{RH} \leq 55 \%$ when compared to the values obtained in the isotherm, irrespective of the sample. As discussed in section 3.1.2, the adsorption of water on ACs at $\mathrm{RH} \leq 40 \%$ is characteristic of the presence of specific (hydrophilic) sites. The fact that the presence of $\mathrm{D} 4$ favors the adsorption of $\mathrm{H}_{2} \mathrm{O}$ in $\mathrm{AC}$ samples for $\mathrm{RH} \leq 40 \%$ could be thus explained by the creation of specific water adsorption sites. These sites could originate, at low $\mathrm{RH}$, from adsorbed D4 itself (e.g. O in Si-O-Si forming hydrogen bonds with $\mathrm{H}_{2} \mathrm{O}$ ).

The behavior of AP4 supports this hypothesis: the absence of competition between D4 and $\mathrm{H}_{2} \mathrm{O}$ would result from the adsorption of $\mathrm{H}_{2} \mathrm{O}$ made possible on adsorbed D4 and in the void space between D4 molecules. For STIX, the competition between D4 and $\mathrm{H}_{2} \mathrm{O}$ is negligible at $25 \% \mathrm{RH}$ and strong at $40 \% \mathrm{RH}$. The absence of competition between D4 and $\mathrm{H}_{2} \mathrm{O}$ at $25 \% \mathrm{RH}$ suggests that the two molecules adsorb on different sites or there is enough space for the adsorption of both. Increasing RH to $40 \%$ leads to a steep drop of the amount of adsorbed D4 accompanied by a steep increase of the water uptake, with only weak change upon further variation of RH. This could be due to the microporous structure of STIX and the presence of hydrophilic sites in the micropores, leading to a complete filling of pores by water already at $\mathrm{P} / \mathrm{P}_{0}=0.4$ when both adsorbates are present. Water clusters increase in size and gain enough dispersive force to fill micropores by capillary condensation, leading to the D4 adsorption capacity loss. Once pores responsible for water adsorption are filled, no more change in the adsorbed phase is expected upon increasing RH. The influence of water on D4 adsorption capacity is strong due to the strong affinity of STIX for water (presence of hydrophilic sites).

A competition between $\mathrm{D} 4$ and $\mathrm{H}_{2} \mathrm{O}$ adsorption can be also observed for AP4 at $\mathrm{RH} \geq 55 \%$, although not in the same level as for STIX. Increasing RH induces a linear decrease of D4 adsorbed amount together with a linear increase of the water uptake. This could be related to 
the pore filling of water in the absence of specific sites. For 207C, a monotonous variation of D4 and water uptakes is observed, which could be related both to the contribution of specific sites, homogenously distributed and in low amounts compared to STIX, and the filling of the porosity. It is evident that in the absence of specific sites (hydrophilic and/or pores with size < $1 \mathrm{~nm}) \mathrm{D} 4$ and $\mathrm{H}_{2} \mathrm{O}$ compete on the same sites.
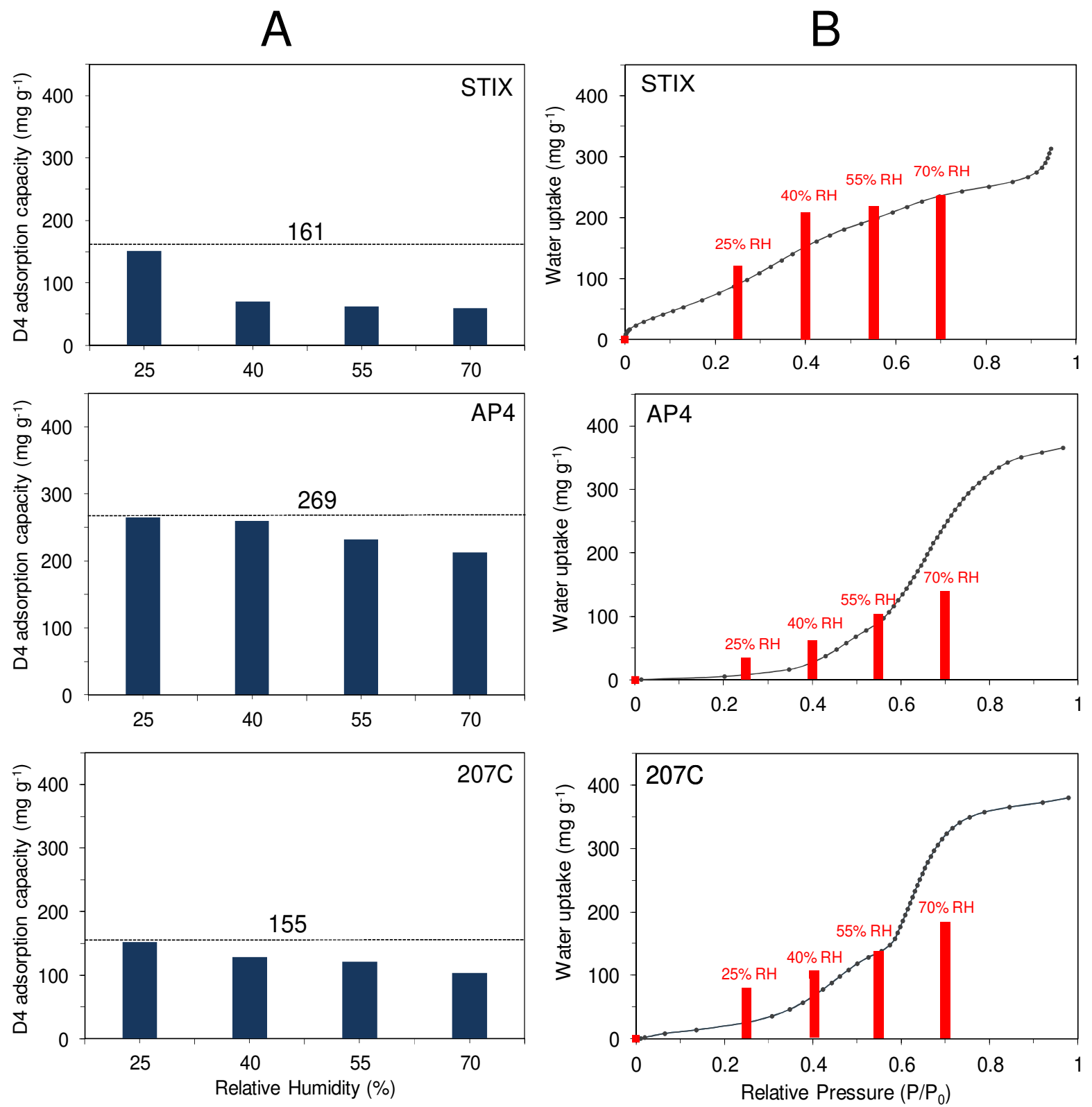

Fig. 7. A) D4 Adsorption capacity of STIX, AP4 and 207C powders measured in the presence of water vapor. The dashed line corresponds to the adsorption capacity measured in the absence of water vapor. B) Water uptakes vs varying RH on STIX, AP4 and 207C in the presence of D4 (red bars). For comparison the water adsorption isotherms are shown (grey curves). Experimental conditions for co-adsorption of $\mathrm{D} 4$ and $\mathrm{H}_{2} \mathrm{O}$ : adsorption temperature = $20 \pm 2{ }^{\circ} \mathrm{C} ; \mathrm{C}_{0}=1000 \mathrm{ppm}(\mathrm{v} / \mathrm{v}) \mathrm{D} 4$ in $\mathrm{N}_{2} ; \mathrm{RH}=25,40,55$ and $70 \%$; flow rate $=5 \mathrm{~L} \mathrm{~h}^{-1}$; sample weight $=100 \mathrm{mg}$. All AC samples were pretreated under $\mathrm{N}_{2}$ at $150{ }^{\circ} \mathrm{C}$ for $2 \mathrm{~h}$. 


\subsection{Ability of ACs to be thermally regenerated after siloxane adsorption}

\subsubsection{Evolution of the D4 adsorption capacity during adsorption/desorption cycles}

In order to study the ability of ACs to be thermally regenerated after siloxane adsorption, two D4 adsorption/thermodesorption cycles were performed. Fig. 8 presents the evolution of D4 adsorption capacities of AC samples during cycling. In similar thermodesorption conditions, AC samples show different regeneration efficiency. AP4 powder demonstrated an excellent performance through 2 cycles without loss of adsorption capacity. The sample was weighed before and after one adsorption/thermodesorption cycle, showing no difference and thus indicating that the thermal treatment at $400{ }^{\circ} \mathrm{C}$ in $\mathrm{N}_{2}$ can fully remove D4 from AP4. On the contrary, STIX capacity to adsorb D4 was greatly reduced from 161 to $103 \mathrm{mg} \mathrm{g}^{-1}$ after the first cycle and further decreased to $77 \mathrm{mg} \mathrm{g}^{-1}$ after the second cycle.

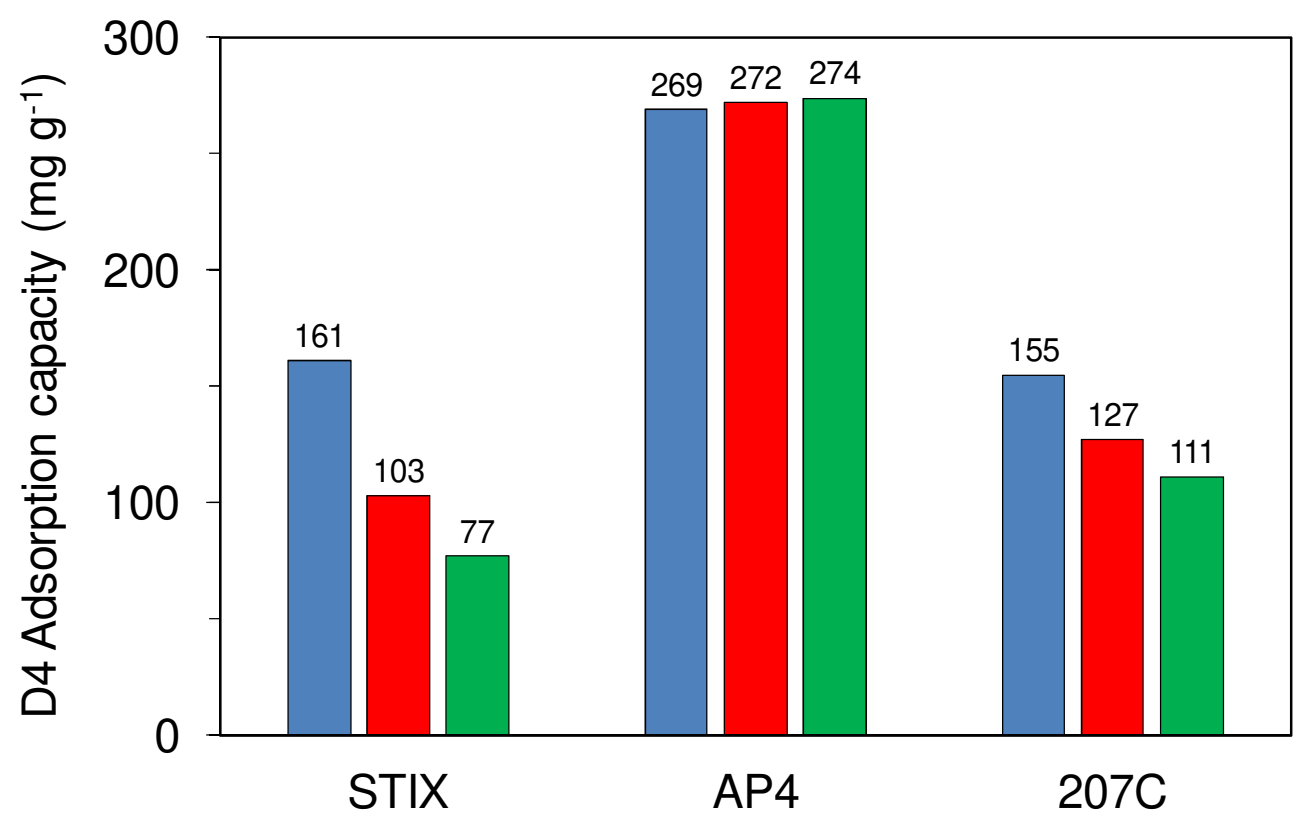

Fig. 8. Variation of D4 adsorption capacity of ACs through adsorption/thermodesorption cycles: $1^{\text {th }}$ adsorption (blue), $2^{\text {nd }}$ adsorption (red), $3^{\text {rd }}$ adsorption (green). Adsorption of D4 $(1000 \mathrm{ppm}(\mathrm{v} / \mathrm{v}))$ in $\mathrm{N}_{2}$ at room temperature $\left(20 \pm 2{ }^{\circ} \mathrm{C}\right)$; adsorption capacity determined from breakthrough curves; thermodesorption up to $400{ }^{\circ} \mathrm{C}\left(5^{\circ} \mathrm{C} \mathrm{min}{ }^{-1}\right)$ under $\mathrm{N}_{2}$ flow $\left(5 \mathrm{~L} \mathrm{~h}^{-1}\right)$.

The D4 adsorption capacity of 207C degrades progressively from $155 \mathrm{mg} \mathrm{g}^{-1}$ for the first adsorption to 127 and $112 \mathrm{mg} \mathrm{g}^{-1}$ for the second and third adsorption step, respectively. Weighing the samples before and after the first adsorption/thermodesorption cycle shows a 
mass gain of 5.1 and $2.3 \%$ for STIX and 207C respectively, indicating the incomplete removal of adsorbed species.

To this respect, the amount of species remaining in the porosity increases after each cycle for STIX and in a lesser extent for 207C (after two cycles the initial D4 adsorption capacity for STIX and 207C loose 52 and 28\%, respectively).

To further understand the parameters responsible for the loss of D4 adsorption capacity, the adsorption/thermodesorption of D4 was investigated by in situ DRIFTS.

\subsubsection{In situ DRIFTS study of D4 thermodesorption from AC}

The adsorption/thermodesorption of D4 on AC was studied by in situ DRIFTS using the same methodology as reported previously [26]. The observation of the adsorbed D4 was made possible only after complete removal of $\mathrm{D} 4$ in gas phase under $\mathrm{N}_{2}$ at room temperature. Observed D4 bands in adsorbed phase for ACs after the D4 adsorption/desorption at room temperature are shown in Table 6. For D4 in gas phase, bands at 1265, 1092 and $816 \mathrm{~cm}^{-1} \mathrm{can}$ be observed, being attributed respectively to $\mathrm{CH}_{3}$ bending, asymmetric $\mathrm{Si}-\mathrm{O}-\mathrm{Si}$ stretching and $\mathrm{CH}_{3}$ rocking modes of $\mathrm{D} 4$ molecule [36]. $\mathrm{Si}-\mathrm{CH}_{3}$ bending and $\mathrm{Si}-\mathrm{O}-\mathrm{Si}$ asymmetric stretching bands are very slightly shifted toward lower wavenumbers for D4 adsorbed on ACs, possibly due to the slight interaction of the molecule with the surface.

Table 6. Attribution of D4 characteristic bands in gas and adsorbed phase for ACs.

\begin{tabular}{lcccc}
\hline Vibration mode & D4 gas phase & D4/STIX & D4/AP4 & D4/207C \\
\hline Symmetric $\mathrm{CH}_{3}$ bending & $1265 \mathrm{~cm}^{-1}$ & $1263 \mathrm{~cm}^{-1}$ & $1261 \mathrm{~cm}^{-1}$ & $1263 \mathrm{~cm}^{-1}$ \\
Asymetric Si-O-Si stretching & $1092 \mathrm{~cm}^{-1}$ & $1090 \mathrm{~cm}^{-1}$ & $1089 \mathrm{~cm}^{-1}$ & $1090 \mathrm{~cm}^{-1}$ \\
$\mathrm{CH}_{3}$ rocking & $816 \mathrm{~cm}^{-1}$ & $816 \mathrm{~cm}^{-1}$ & $816 \mathrm{~cm}^{-1}$ & $816 \mathrm{~cm}^{-1}$ \\
\hline
\end{tabular}

The spectral evolutions of STIX, AP4 and 207C samples during the D4 thermodesorption are shown in Fig. 9. The AP4 spectra exhibit characteristic bands of D4 in the gas phase, indicating the desorption of D4 from AP4. The band intensity rises progressively from $25^{\circ} \mathrm{C}$ up to a maximum at $200{ }^{\circ} \mathrm{C}$ and then decreases until complete disappearance at $400{ }^{\circ} \mathrm{C}$. It can be concluded that D4 desorption from AP4 takes place between 25 and $400{ }^{\circ} \mathrm{C}$ with a 
maximum desorption rate around $200{ }^{\circ} \mathrm{C}$. The result is also in agreement with the desorption completion at $400{ }^{\circ} \mathrm{C}$ revealed in section 3.3.1. STIX and 207C samples show a different behavior during thermodesorption. Below $150{ }^{\circ} \mathrm{C}$ for STIX and $180{ }^{\circ} \mathrm{C}$ for $207 \mathrm{C}$, the appearance of the bands at 1265,1092 and $815 \mathrm{~cm}^{-1}$ corresponds to the release of D4 in the gas phase. Above these temperatures, a new band at $1035 \mathrm{~cm}^{-1}$ appears. The appearance of this band shows that other siloxane species are desorbing from the samples.

Table 7 gathers the characteristic IR bands of different linear and cyclic (gas phase) siloxanes in the $1300-800 \mathrm{~cm}^{-1}$ region [37-40].
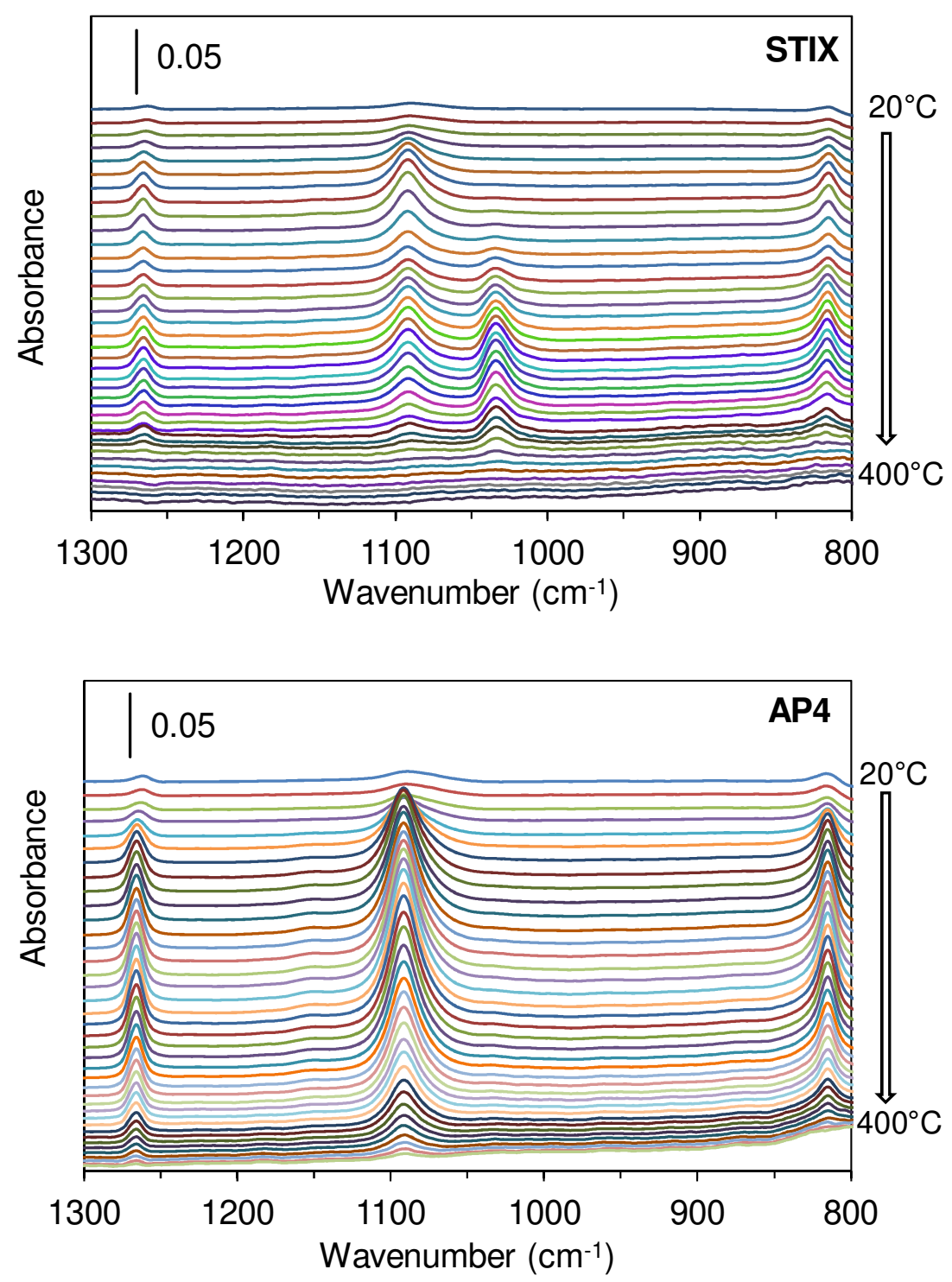


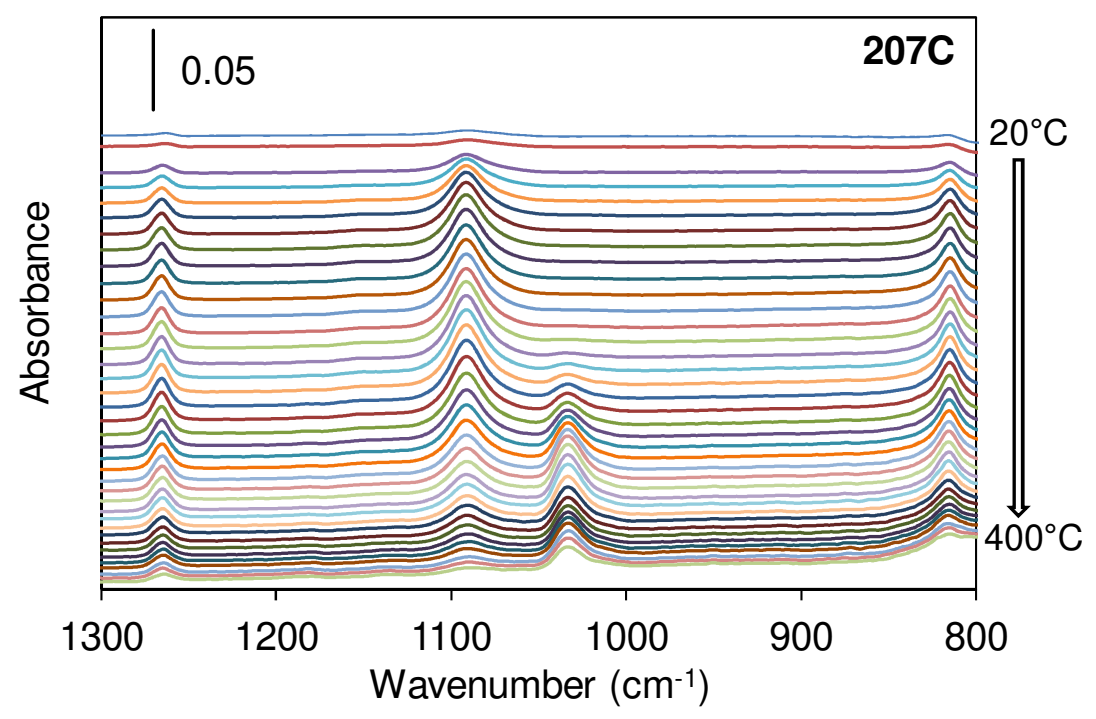

Fig. 9. Spectral evolution of ACs (adsorbed and gas phases) during thermodesorption from 20 up to $400{ }^{\circ} \mathrm{C}\left(5^{\circ} \mathrm{C} \mathrm{min}^{-1}\right)$ under $\mathrm{N}_{2}$ flow $\left(5 \mathrm{~L} \mathrm{~h}^{-1}\right)$. Spectra collected every $10{ }^{\circ} \mathrm{C}$.

Table 7. Assignment of IR stretching, bending and rocking vibrations of some linear and cyclic siloxanes in gas phase from literature [38-40]. Characteristic IR vibrations of solid polydimethylsiloxane (PDMS) are also given [37,41].

\begin{tabular}{|c|c|c|c|}
\hline Molecule & $\mathrm{CH}_{3}$ bending & Si-O-Si stretching & $\mathrm{CH}_{3}$ rocking \\
\hline L2 & 1262 & 1074 & 851 \\
\hline L3 & 1263 & 1089,1064 & 848,808 \\
\hline L4 & 1264 & 1089,1054 & 847,802 \\
\hline L5 & 1265 & 1097,1047 & 846,802 \\
\hline D3 & 1264 & 1035 & 818 \\
\hline D4 & 1266 & 1093 & 812 \\
\hline D5 & 1265 & 1095 & 802 \\
\hline PDMS* (solid) & 1262 & 1097,1024 & . \\
\hline
\end{tabular}

* an IR band at $913 \mathrm{~cm}^{-1}$ (strong) is also observed for PDMS and attributed to $\mathrm{Si}-\mathrm{H}, \mathrm{Si}-\mathrm{H}_{2}$ wagging [37]

From data in Table 7, the band at $1035 \mathrm{~cm}^{-1}$ can be unambiguously attributed to the asymmetric Si-O-Si stretch vibration of D3. D3 exhibits also vibration bands at 1264 and 818 $\mathrm{cm}^{-1}$, overlapping those of D4 (1266 and $\left.815 \mathrm{~cm}^{-1}\right)$. The detection of linear compounds in the released gases is excluded due to the absence of a characteristic doublet in the $1100-1000 \mathrm{~cm}^{-}$ ${ }^{1}$. On the contrary the release of other cyclic siloxanes than D4 and D3 cannot be excluded due to the similarity of the IR spectra of these molecules with D4 between $1300-800 \mathrm{~cm}^{-1}$. 
The appearance of D3 in gas phase during thermodesorption up to $400{ }^{\circ} \mathrm{C}$ for STIX and 207C seems to be related to the inability of the AC to be completely regenerated. This allows concluding that D4 is transformed on these samples into other siloxane type compounds while no such conversion proceeds on AP4.

\subsection{Discussion}

The transformation of adsorbed D4 in ACs into larger cyclic compounds (mainly D5, D6 and D7) has been previously observed based on extraction in hexane after prolonged contact of the ACs at room temperature with D4 [13]. In the present study, such molecules forming inside carbon porosity could not be evidenced due to spectral features similar to that of D4. It is also known that linear polysiloxanes, such as PDMS, can be formed by polymerization of cyclic siloxanes [42]. The clear observation of D3 desorbing in gas phase during the thermodesorption treatment is consistent with the formation of PDMS or linear polysiloxanolate, the intermediate species in the formation of PDMS (see scheme 1). The thermal degradation of PDMS in inert atmosphere results in depolymerization and production of cyclic oligomers, D3 being the most abundant product with decreasing amounts of higher oligomers [37]. Polymerization of D4 involves the ring opening of the cyclic molecule as a first step. Two routes are possible: the one based on the use of strong inorganic, organic or organometallic bases (anionic mechanism), the one involving both Brønsted and Lewis acid catalysts (cationic mechanism) [42]. The latter mechanism was suggested by Cabrera Codony [13] to explain the polymerization of D4 adsorbed in activated carbon at room temperature depending on the contact time. A correlation was found between the polymerization of adsorbed D4 measured and the O/C ratio determined by XPS and TPD, and more specifically the amount of phenolic and carboxylic groups. From the results in this study, the O/C ratios determined by XPS are equal to 0.04, 0.05 and 0.1 for STIX, AP4 and 207C respectively. STIX and AP4 presenting similar O/C ratios exhibit opposite behavior with respect to polymerization during the thermodesorption. On this basis, the cationic mechanism seems to be unlikely for ACs studied here.

Concerning the anionic mechanism, strong basic sites are needed. Based on the results obtained by Boehm titration, the basicity of the different ACs varies in the order 207C < AP4 $<$ STIX. No direct correlation can be established between the total basic character of ACs and the fact that the polymerization takes place only on STIX and 207C. It must be pointed out that the nature of the basic sites on activated carbon surfaces is far from being understood. 
Oxygen-containing groups ( $\gamma$ pyrone-type, chromene, diketone or quinone groups), delocalized $\pi$-electrons of the basal planes, nitrogen-containing groups, inorganic impurities are assumed to be responsible for the basic character [43]. The knowledge of the strength of these basic sites, and their contribution to the overall carbon basicity is still challenging. The anionic mechanism requires strong basic sites which might be present in STIX and 207C but not in AP4. Looking at the chemical composition of the ACs, there seems to be a relationship between the degree of polymerization and the amount of alkali metals $(\mathrm{K}, \mathrm{Na})$ : the higher the quantity of alkali metals, the higher the D4 fraction polymerized as revealed by the capacity loss. Alkali metals could appear as a marker of strong basic sites. They could also be identified as the specific hydrophilic sites revealed by $\mathrm{H}_{2} \mathrm{O}$ adsorption. Similar loss of capacity is observed upon thermal treatments and during co-adsorption of D4 and $\mathrm{H}_{2} \mathrm{O}$.

Semi-quantitative assessments were further derived from FTIR data of desorption experiments. The normalized evolution of the intensity of the bands at $1092 \mathrm{~cm}^{-1}$ (characteristic of D4 gas) and at $1035 \mathrm{~cm}^{-1}$ (characteristic of D3 gas) during thermal treatment after the adsorption step over STIX, AP4 and $207 \mathrm{C}$ at $20{ }^{\circ} \mathrm{C}$ is reported in Fig. 10. For AP4, a broad peak corresponding to D4 desorption is observed with a maximum rate of $\mathrm{Si}-\left(\mathrm{CH}_{3}\right)_{2}$ groups released at $190{ }^{\circ} \mathrm{C}$. After such thermal treatment, the AP4 absorption capacity is completely restored. For STIX, the release of D4 is observed in between 50 and $350{ }^{\circ} \mathrm{C}$, with curve splitting in two maxima: 100 and ca. $200{ }^{\circ} \mathrm{C}$. The first peak could be attributed to desorption of previously adsorbed D4 (without conversion) while the second peak would result from D4 formed by decomposition of polysiloxanolate/PDMS. The latter phenomenon would be accompanied by the release of D3, thus confirming the degradation of polysiloxanolate/PDMS. Although no more desorption occurs above $350{ }^{\circ} \mathrm{C}$, this cannot be attributed to a complete regeneration of STIX. The partial filling of the STIX porosity is supported by the results in Fig. 8, showing the D4 adsorption capacity after thermodesorption is not recovered. 

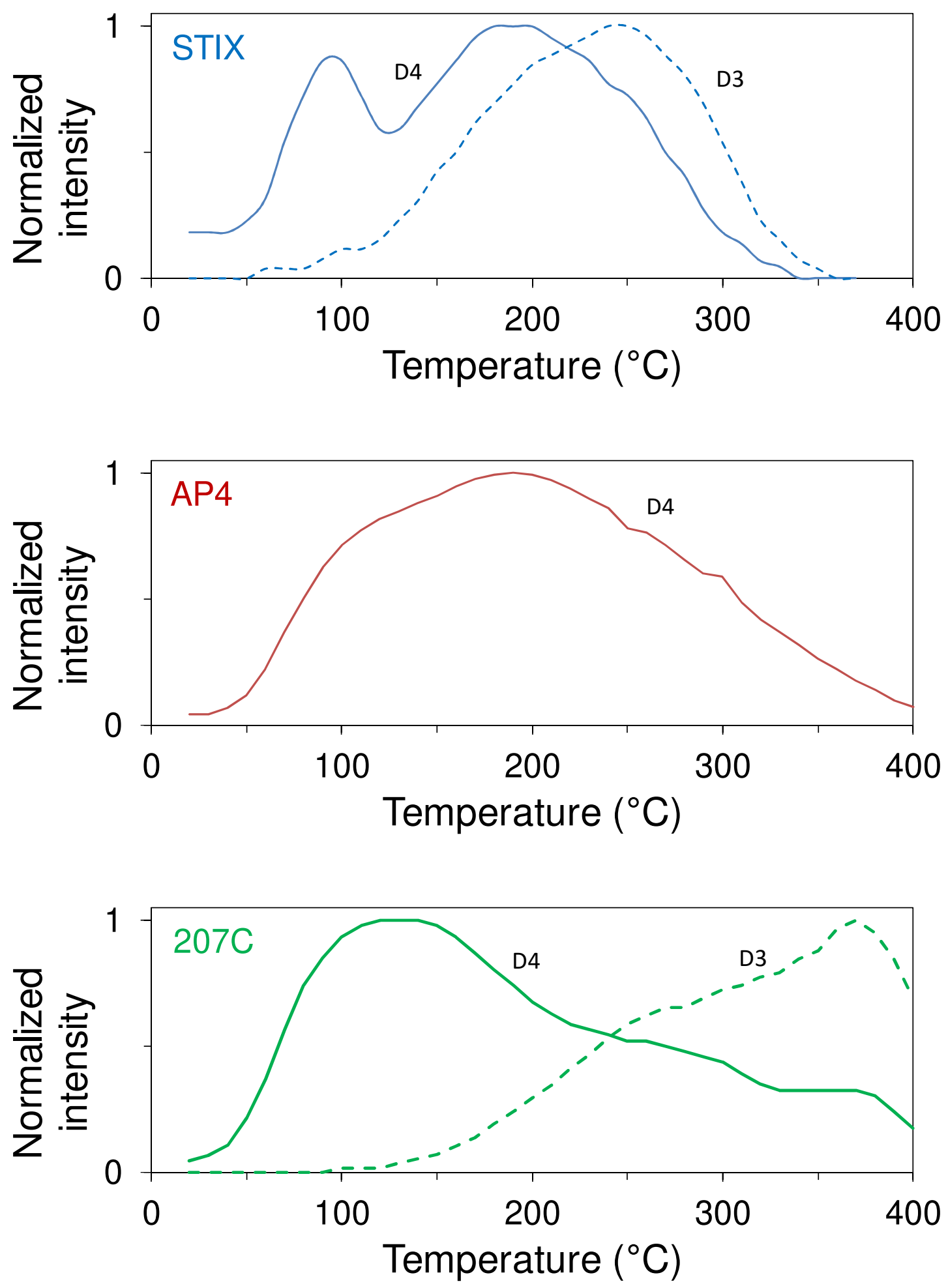

Fig. 10. Normalized evolution of the intensity of the bands at $1092 \mathrm{~cm}^{-1}$ (characteristic of D4 gas) and at $1035 \mathrm{~cm}^{-1}$ (characteristic of D3 gas) during thermal treatment after the adsorption step over STIX, AP4 and $207 \mathrm{C}$ at $20^{\circ} \mathrm{C}$. Thermodesorption conditions: heating from 20 to $400{ }^{\circ} \mathrm{C}\left(5{ }^{\circ} \mathrm{C} \mathrm{min}^{-1}\right)$ under $\mathrm{N}_{2}$ flow $\left(5 \mathrm{~L} \mathrm{~h}^{-1}\right)$ and spectra collected every $10{ }^{\circ} \mathrm{C}$. 
207C sample shows a different behavior compared to STIX and AP4. A maximum of desorption rate of $\mathrm{D} 4$ is observed at ca. $120{ }^{\circ} \mathrm{C}$ simultaneously to the appearance of D3 in gas phase. The rate of formation of D3 continuously increases up to ca. $380{ }^{\circ} \mathrm{C}$ while that of D4 decreases monotonously until $400{ }^{\circ} \mathrm{C}$. According to the hypothesis proposed previously for STIX, it may be suggested that, below $120^{\circ} \mathrm{C}$, the adsorbed D4 is desorbed while, above this temperature, decomposition products of polysiloxanolate/PDMS trapped in the porosity are observed. It is worthwhile mentioning that desorption is not complete at $400{ }^{\circ} \mathrm{C}$, which can explain the loss of adsorption capacity (Fig. 8).

The different evolution of D4 and D3 in the gas phase between STIX and 207C can be explained by different rates of formation/decomposition of polysiloxanolate/PDMS.

The mechanism of formation of linear polysiloxanolate via ring-opening reaction and its thermal decomposition in smaller cyclic oligomers is given in Fig. 11. Interestingly, the termination of the polymerization process requires some acidity so that the silanolate centre can be deactivated and PDMS formed.

For STIX, with increasing temperature, the rate of D4 polymerization seems to exceed that of polysiloxanolate/PDMS depolymerization, so that there is accumulation of non-volatile polymer in its porosity. Based on the results in Fig. 8, this process continue during the successive D4 adsorption/desorption cycles resulting into degradation of STIX probably until complete loss of its adsorptive properties. Contrary to STIX, on 207C the rate of the PS/PDMS thermal degradation exceeds that of its formation which can explain the presence of increasing D3 concentration in gas phase (simultaneously with continuous decrease of desorbed D4) with increasing temperature. Better regenerability of 207C compared with STIX can be explained by less or no polymer accumulated during thermal treatment. It can be observed in Fig. 10 that above $380{ }^{\circ} \mathrm{C}$ the rate of $\mathrm{D} 3$ evolved in the gas phase decreases and possibly the powder could be completely regenerated by using temperatures higher than 400 ${ }^{\circ} \mathrm{C}$. The different polymerization behavior between STIX and 207C could be related to the $\mathrm{K}$ concentration, being 5 times higher in STIX than in 207C (Table 2).

Concerning the adsorptive properties, no linear correlation between the D4 adsorption capacity and the textural properties of the samples studied here could be found (Fig. 6) as generally invoked in the literature. Among other parameters that can also play a role on the AC adsorption properties, the reactivity of D4 at room temperature can be considered. In order to explain the lower D4 adsorption capacities at room temperature of STIX/207C compared to AP4, it could be proposed that D4 reacts in STIX/207C during the adsorption, 
leading to the formation of species, such as siloxanolate, blocking the entrance of the empty pores and thus dramatically decreasing the adsorption capacity.

The exceptional behavior of AP4 in adsorption/desorption of D4 could be related to the absence of active sites for D4 transformation.

Step 1: Polymerization

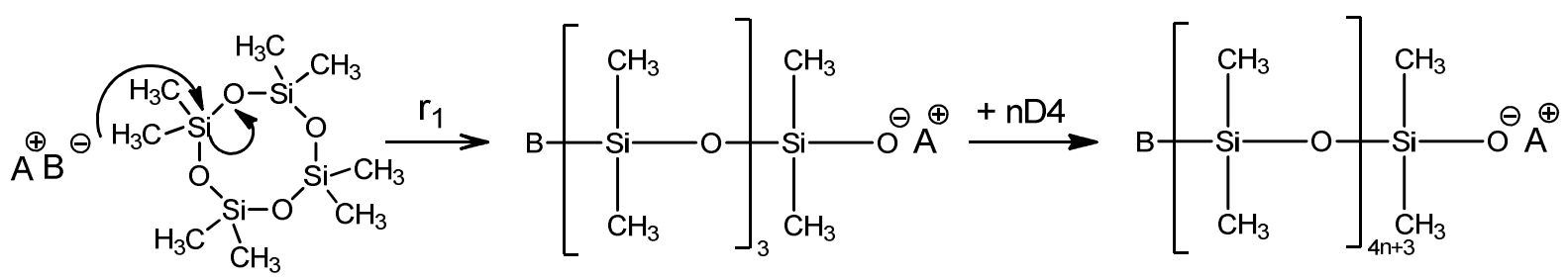

Octamethylcyclotetrasiloxane (D4)

PolySiloxanolate $[\mathrm{PS}]_{\mathrm{m}}$

Step 2: Depolymerization<smiles>C[Si](C)(O)O[Si]1(C)O[Si](C)(C)O[Si](C)(C)O[Si]1(C)O[Si](C)(C)O[Si](C)(C)[18OH]</smiles>

$[\mathrm{PS}]_{\mathrm{m}}$<smiles>C[Si]1(C)O[Si](C)(C)O[Si](C)(C)O1</smiles>

Hexamethylcyclotrisiloxane (D3)<smiles>[B][Si](C)([O])O[Si]1(C)O[Si](C)(C)O[Si](C)(C)O[Si](C)(C)O[Si](C)(C)O[Si](C)(C)O1</smiles>

$[\mathrm{PS}]_{\mathrm{m}}$<smiles>C[Si]1(C)O[Si](C)(C)O[Si](C)(C)O[Si](C)(C)O1</smiles>

Octamethylcyclotetrasiloxane (D4)

Fig. 11. Mechanism of formation/decomposition of linear polysiloxanolate (PS) from D4. $\mathrm{A}^{+}$ would be an alkaline metal cation $(\mathrm{K}, \mathrm{Na})$ and $\mathrm{B}^{-}$the associated basic site. 


\section{Conclusion}

Three commercial activated carbon samples chosen for their sorbent properties in air and gas treatment have been tested in D4 adsorption and thermodesorption in view of biogas purification. The main scope was the understanding of the parameters influencing the thermal regenerability of ACs after D4 adsorption and the adsorption properties in the presence of humidity.

Different D4 adsorption capacities were measured without clear relationship with textural properties (surface area, porosity).

Isotherms of water adsorption at room temperature revealed the existence of varying amounts of hydrophilic sites. The presence of these sites was shown to influence the D4 adsorption in the presence of humidity (present in biogas). The textural properties and the $\mathrm{RH}$ are the others factors playing a role in the co-adsorption of D4 and $\mathrm{H}_{2} \mathrm{O}$. In the porosity accessible to D4, the presence of hydrophilic sites induces a strong loss of D4 adsorption capacity, due to the preferential adsorption of water. In the absence of hydrophilic sites the competition between $\mathrm{H}_{2} \mathrm{O}$ and $\mathrm{D} 4$ is weaker and progressive, starting for $\mathrm{RH} \geq 55 \%$.

Upon thermal treatment up to $400{ }^{\circ} \mathrm{C}$ after D4 adsorption at $20{ }^{\circ} \mathrm{C}$, the formation of polysiloxanolate/PDMS molecules is proposed to take place in the porosity of ACs containing alkali metal cations and inhibit the regenerability. In the absence of such sites, the regeneration was complete. The ring-opening of D4 with formation of polysiloxanalolate type species could also be responsible for limiting the D4 uptake in STIX and 207C by partial blockage of the entrance of the large micropores. The absence of such reactivity in AP4 would explain the exceptional behavior of AP4 in D4 in terms of D4 adsorption/desorption.

This work sheds some light on the importance of surface chemistry and textural properties in designing activated carbons with good capacity of regeneration after siloxane adsorption and low sensitivity to humidity.

\section{Acknowledgements}

The authors would like to thank the French Ministry of Higher Education and Research for V.T.L. Tran PhD funding. Authors gratefully acknowledge L. Cardenas for XPS analyses.

\section{References}


[1] N. De Arespacochaga, C. Valderrama, J. Raich-Montiu, M. Crest, Understanding the effects of the origin, occurrence, monitoring, control, fate and removal of siloxanes on the energetic valorization of sewage biogas - A review, Renew. Sustain. Energy Rev. 52 (2015) 366-381.

[2] R. Dewil, L. Appels, J. Baeyens, Energy use of biogas hampered by the presence of siloxanes, Energy Convers. Manag. 47 (2006) 1711-1722.

[3] R. Niessner, M. Schweigkofler, Determination of Siloxanes and VOC in Landfill Gas and Sewage Gas by Canister Sampling and GC-MS / AES Analysis, Environ. Sci. Technol. 33 (1999) 3680-3685.

[4] S. Rasi, J. Lehtinen, J. Rintala, Determination of organic silicon compounds in biogas from wastewater treatments plants, land fills, and co-digestion plants, Renew. Energy 35 (2010) 2666-2673.

[5] B. Tansel, S.C. Surita, Differences in volatile methyl siloxane (VMS) profiles in biogas from landfills and anaerobic digesters and energetics of VMS transformations, Waste Manag. 34 (2014) 2271-2277.

[6] G. Soreanu, M. Be, P. Falletta, K. Edmonson, L. Svoboda, M. Al-Jamal, P. Seto, Approaches concerning siloxane removal from biogas - A review, Can. Biosyst. Eng. 53 (2011) 1-18.

[7] P. Gislon, S. Galli, G. Monteleone, Siloxanes removal from biogas by high surface area adsorbents, Waste Manag. 33 (2013) 2687-2693.

[8] D. Ricaurte Ortega, A. Subrenat, Elimination of siloxanes by adsorption process as a way of upgrading biogas, Trans. Ecol. Environ. (Energy and Sustainability II) 121 (2009) 49-58.

[9] E. Finocchio, T. Montanari, G. Garuti, C. Pistarino, F. Federici, M. Cugino, G. Busca, Purification of Biogases from Siloxanes by Adsorption: On the Regenerability of Activated Carbon Sorbents, Energy \& Fuels 23 (2009) 4156-4159.

[10] T. Matsui, S. Imamura, Removal of siloxane from digestion gas of sewage sludge, Bioresour. Technol. 101 (2010) 29-32.

[11] M. Yu, H. Gong, Z. Chen, M. Zhang, Adsorption characteristics of activated carbon for siloxanes, J. Environ. Chem. Eng. 1 (2013) 1182-1187.

[12] K. Oshita, Y. Ishihara, M.Takaoka, N. Takeda, T. Matsumoto, S. Morisawa, A. Kitayama, Behaviour and Adsorptive Removal of Siloxanes in Sewage Sludge Biogas, Water Sci. Technol. 61 (2010) 2003-2012.

[13] A. Cabrera-Codony, M.A. Montes-Mora, M. Sa, M.J. Mart, R. Gonzalez-Olmos, Biogas Upgrading: Optimal Activated Carbon Properties for Siloxane Removal, Environ. Sci. Technol. 48 (2014) 7187-7195.

[14] E. Santos-Clotas, A. Cabrera-Codony, B. Ruiz, E. Fuente, M.J. Martin, Sewage biogas efficient purification by means of lignocellulosic waste-based activated carbons, Bioresource Technology 275 (2019) 207-215.

[15] A. Cabrera-Codony, E. Santos-Clotas, C.O. Ania, M.G. Martin, Competitive siloxane 
adsorption in multicomponent gas streams for biogas upgrading. Chemical Engineering Journal, 344 (2018) 565-573.

[16] J.L. Figueiredo, M.F.R. Pereira, The role of surface chemistry in catalysis with carbons, Catal. Today 150 (2010) 2-7.

[17] H. Gong, Z. Chen, Y. Fan, M. Zhang, W. Wu, W. Wang, Surface modification of activated carbon for siloxane adsorption, Renew. Energy 83 (2015) 144-150.

[18] I. Angelidaki, L. Treu, P. Tsapekosa, G. Luo, S. Campanaro, H. Wenzel, P.G. Kougias, Biogas upgrading and utilization: Current status and perspectives, Biotechnol. Adv. 36 (2018) 452-466.

[19] N. de Arespacochaga, C. Valderrama, C. Mesa, L. Bouchy, J.L. Cortina, Biogas deep clean-up based on adsorption technologies for Solid Oxide Fuel Cell applications, Chem. Eng. J. 255 (2014) 593-603.

[20] E. Ryckebosch, M. Drouillon, H. Vervaeren, Techniques for transformation of biogas to biomethane, Biomass Bioenergy 35 (2011) 1633-1645.

[21] L. Liu, S. Tan, T. Horikawa, D.D. Do, D. Nicholson, J. Liu, Water adsorption on carbon - A review, Adv. Colloid. Interface Sci. 250 (2017) 64-78.

[22] N. Qi, W.S. Appel, M.D. LeVan, Adsorption Dynamics of Organic Compounds and Water Vapor in Activated Carbon Beds, Ind. Eng. Chem. Res. 45 (2006) 2303-2314.

[23] M. Ajhar, M. Travesset, S. Yuce, T. Melin, Siloxane removal from landfill and digester gas - A technology overview, Bioresour. Technol. 101 (2010) 2913-2923.

[24] S. Giraudet, B. Boulinguiez, P. Le Cloirec, Adsorption and Electrothermal Desorption of Volatile Organic Compounds and Siloxanes onto an Activated Carbon Fiber Cloth for Biogas Purification, Energy \& Fuels 28 (2014) 3924-3932.

[25] J. Jagiello, J.P. Olivier, Carbon slit pore model incorporating surface energetical heterogeneity and geometrical corrugation, Adsorption (2013) 777-783.

[26] V.T.L. Tran, P. Gélin, C. Ferronato, L. Fine, J.M. Chovelon, G. Postole, Exploring the potential of infrared spectroscopy on the study of the adsorption/desorption of siloxanes for biogas purification, Catal. Today 306 (2018) 191-198.

[27] H.P. Boehm, Some aspects of the surface chemistry of carbon blacks and other carbons, Carbon 32 (1994) 759-769.

[28] C.A. Leon y Leon, J.M. Solar, V. Calemma, L.R. Radovic, Evidence for the protonation of basal plane sites on carbon, Carbon 30 (1992) 797-811.

[29] M. Smith, L. Scudiero, J. Espinal, J.S. McEwen, M. Garcia-Perez, Improving the deconvolution and interpretation of XPS spectra from chars by ab initio calculations, Carbon 110 (2016) 155-171.

[30] E. Desimoni, G.I. Casella, A. Morone, A.M. Salvi, XPS Determination of Oxygencontaining Functional Groups on Carbon-fibre Surfaces and the Cleaning of These Surfaces, Surf. Interface Anal. 15 (1990) 627-634.

[31] M. Thommes, J. Morell, K. A. Cychosz, M. Fröba, Combining Nitrogen, Argon, and 
Water Adsorption for Advanced Characterization of Ordered Mesoporous Carbons (CMKs) and Periodic Mesoporous Organosilicas (PMOs), Langmuir 29 (2013) 14893-14902.

[32] M. Thommes, S. Mitchell, J. Pérez-Ramírez, Surface and Pore Structure Assessment of Hierarchical MFI Zeolites by Advanced Water and Argon Sorption Studies, J. Phys. Chem. C 116 (2012) 18816-18823.

[33] K.S.W. Sing, D.H. Everett, R.A.W. Haul, L. Moscou, R.A. Pierotti, J. Rouquérol, T. Siemieniewska, Reporting Physisorption Data for Gas/Solid Systems With Special Reference to the Determination of Surface Area and Porosity, Pure Appl. Chem. 57 (1985) 603-619.

[34] N. Foley, K. Thomas, P. Forshaw, Kinetics of water vapor adsorption on activated carbon, Langmuir 101 (1997) 2083-2089.

[35] F. Carrasco-Marin, A. Mueden, T.A. Centeno, F. Stoeckli, C. Moreno-Castilla, Water adsorption on activated carbons with different degrees of oxidation, J. Chem. Soc. Faraday Trans. 93 (1997) 2211-2215.

[36] T. Alvik, J. Dales, Infrared and raman spectra of cyclic dimethylsiloxane oligomers, Acta Chem. Scand. 25 (1971) 2142-2148.

[37] G. Camino, M.S. Momakin, M. Lageard, Thermal polydimethylsiloxane degradation. Part 2. The degradation mechanisms, Polymer 43 (2002) 2011-2015.

[38] S. Wachholz, F. Keidel, U. Just, H. Geissler, K. Käppler, Analysis of a mixture of linear and cyclic siloxanes by cryo-gas chromatography-Fourier transform infrared spectroscopy and gas chromatography-mass spectrometry, J. Chromatography A 693 (1995) 89-99.

[39] C. Carteret, A. Labrosse, Vibrational properties of polysiloxanes: from dimer to oligomers and polymers. 1. Structural and vibrational properties of hexamethyldisiloxane $\left(\mathrm{CH}_{3}\right)_{3} \mathrm{SiOSi}\left(\mathrm{CH}_{3}\right)_{3}$, J. Raman Spectroscopy 41 (2010) 9961004.

[40] F. Bernard, D.K. Papanastasiou, V.C. Papadimitriou, J.B. Burkholder, Infrared absorption spectra of linear (L2-L5) and cyclic (D3-D6) permethylsiloxanes, J. Quantitative Spectroscopy \& Radiative Transfer 202 (2017) 247-254

[41] D. Cai, A. Neyer, R. Kuckuk, H.M. Heise, Raman, mid-infrared, near-infrared and ultraviolet-visible spectroscopy of PDMS silicone rubber for characterization of polymer optical waveguide materials, J. Molec. Struct. 976 (2010) 274-281.

[42] J. Chojnowski, M. Cypryk (2000) Synthesis of Linear Polysiloxanes. In: Jones R.G., Ando W., Chojnowski J. (eds) Silicon-Containing Polymers. Springer, Dordrecht, p. 341 .

[43] M.A. Montes-Moran, D. Suarez, J.A. Menendez, E. Fuente, On the nature of basic sites on carbon surfaces: An overview, Carbon 42 (2004) 1219-1225. 
Siloxane adsorption on activated carbons: role of the surface chemistry on sorption properties in humid atmosphere and regenerability issues.

Vu Tung Lam Tran, Patrick Gélin, Corinne Ferronato, Pascale Mascunan, Vladislav Rac, Jean-Marc Chovelon, Georgeta Postole

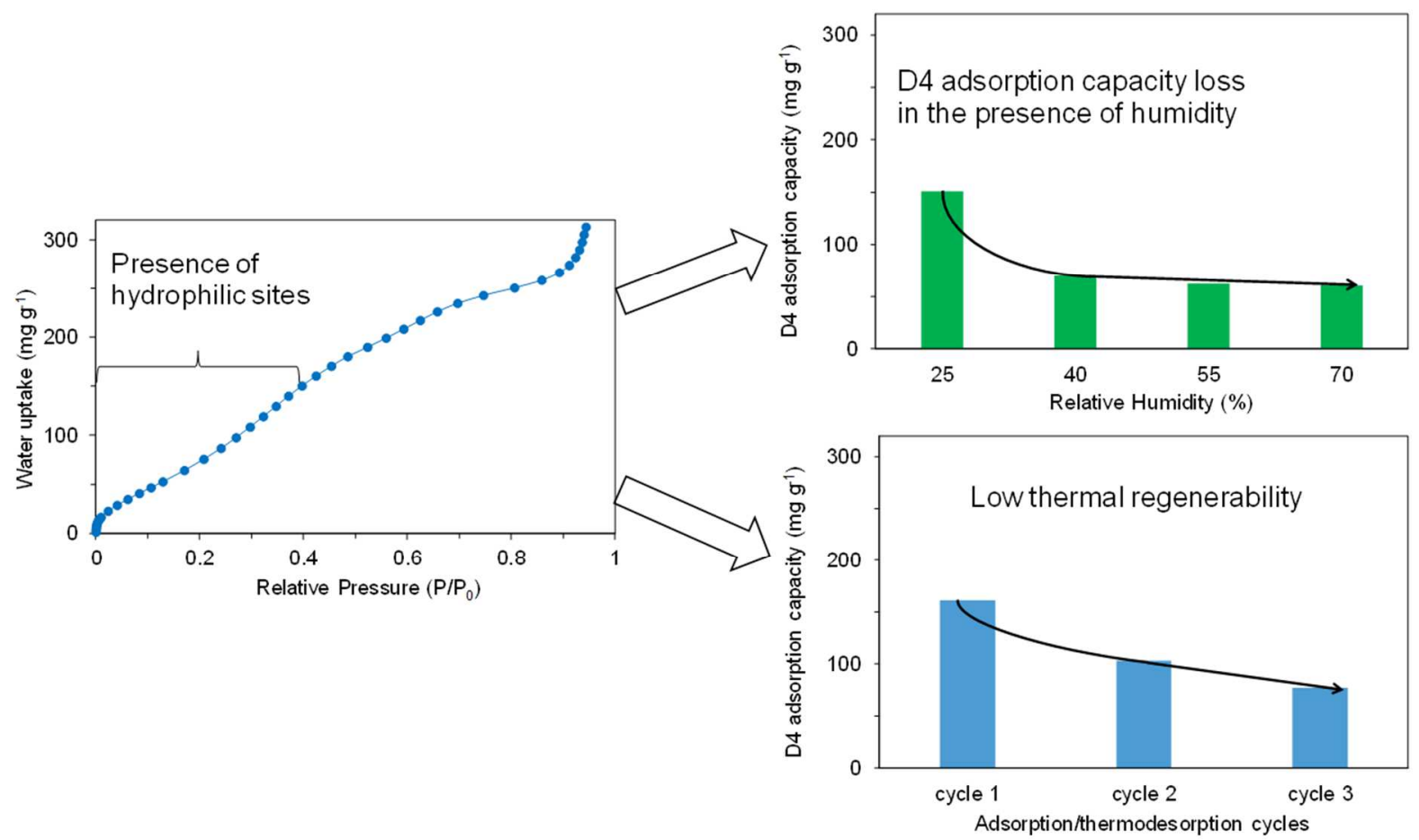

